\title{
Control of cytokinesis by $\beta$-adrenergic receptors indicates an approach for regulating cardiomyocyte endowment
}

Honghai Liu ${ }^{1, \dagger}$, Cheng-Hai Zhang ${ }^{2,3, \dagger}$, Niyatie Ammanamanchi ${ }^{1, \dagger}$, Sangita Suresh $^{2,4}$, Christopher Lewarchik ${ }^{1}$, Krithika Rao ${ }^{1}$, Gerrida M. Uys ${ }^{2,5}$, Lu Han ${ }^{1}$, Maryline Abrial ${ }^{2,6}$, Dean Yimlamai $^{7}$, Balakrishnan Ganapathy ${ }^{1,8}$, Christelle Guillermier ${ }^{9}$, Nathalie Chen ${ }^{1}$, Mugdha Khaladkar $^{10,11}$, Jennifer Spaethling ${ }^{12}$, James H. Eberwine ${ }^{12}$, Junhyong Kim ${ }^{10}$, Stuart Walsh ${ }^{2,13}$, Sangita Choudhury ${ }^{2,14}$, Kathryn Little ${ }^{1}$, Kimberly Francis ${ }^{1}$, Mahesh Sharma ${ }^{19}$, Melita Viegas ${ }^{15}$, Abha Bais ${ }^{16}$, Dennis Kostka ${ }^{16}$, Jun Ding ${ }^{17}$, Ziv Bar-Joseph ${ }^{17}$, Yijen Wu ${ }^{16}$, Matthew L. Steinhauser ${ }^{9}$, Bernhard Kühn ${ }^{1,18,20 *}$

\section{Affiliations:}

${ }^{1}$ Richard King Mellon Foundation Institute for Pediatric Research and Division of Cardiology, UPMC Children's Hospital of Pittsburgh and Department of Pediatrics, University of Pittsburgh, Pittsburgh, PA 15224, USA.

${ }^{2}$ Department of Cardiology, Boston Children's Hospital, Boston, MA 02115, USA and

Department of Pediatrics, Harvard Medical School, Boston, MA 02115, USA.

${ }^{3}$ Current address: Department of Biological Chemistry \& Molecular Pharmacology, Harvard Medical School, Boston, MA 02115, USA.

${ }^{4}$ Current address: Roche Sequencing Solutions, Madison, WI 53719, USA.

${ }^{5}$ Current address: HealthQ Technologies, Stellenbosch, South Africa.

${ }^{6}$ Current address: Cardiovascular Research Institute, Massachusetts General Hospital, Boston, MA 02129, USA.

${ }^{7}$ Department of Pediatric Gastroenterology, Hepatology and Nutrition, Children's Hospital of Pittsburgh of UPMC, Pittsburgh, PA 15224, USA.

${ }^{8}$ Current address: Biogen, Cambridge, MA 02142, USA.

${ }^{9}$ Brigham \& Women's Hospital, Division of Genetics and Harvard Medical School, Boston, MA 02115, USA.

${ }^{10}$ Department of Biology, School of Arts and Sciences, University of Pennsylvania, 301A/B

Lynch Laboratory, 433 S University Avenue, Philadelphia, PA 19104, USA.

${ }^{11}$ Current address: GlaxoSmithKline, Philadelphia, PA 19112, USA.

${ }^{12}$ Department of Systems Pharmacology and Translational Therapeutics, Perelman School of Medicine, University of Pennsylvania, Philadelphia, PA 19104, USA.

${ }^{13}$ Current address: Bayer Healthcare, 42096 Wuppertal, Germany. 
${ }^{14}$ Current address: Department of Genetics and Genomics, Boston Children's Hospital, Boston, MA 02115, USA.

15 Pediatric Cardiothoracic Surgery, Children's Hospital of Pittsburgh of UPMC and Department of Cardiothoracic Surgery, University of Pittsburgh, Pittsburgh, PA 15224, USA.

${ }^{16}$ Department of Developmental Biology, Rangos Research Center, Children's Hospital of Pittsburgh of UPMC, Pittsburgh, PA 15224, USA.

${ }^{17}$ Computational Biology Department and Machine Learning Department, Carnegie Mellon University, Pittsburgh. PA 15213.

${ }^{18}$ McGowan Institute of Regenerative Medicine, Pittsburgh, PA 15219, USA.

${ }^{19}$ Division of Cardiothoracic Surgery, The University of North Carolina at Chapel Hill, Chapel Hill, NC 27599

${ }^{20}$ Pediatric Institute for Heart Regeneration and Therapeutics (I-HRT), Pittsburgh, PA 15224, USA.

$\dagger$ Equally contributing authors.

*Correspondence should be addressed to:

Bernhard Kühn

UPMC Children's Hospital of Pittsburgh, Richard King Mellon Foundation Institute for Pediatric Research

4401 Penn Ave

Pittsburgh, PA 15224-1334

Bernhard.kuhn2@,CHP.edu

Office: 412-692-9909 


\section{ABSTRACT/SUMMARY}

One million patients with congenital heart disease (CHD) live in the US. They have a lifelong risk of developing heart failure. Current concepts do not sufficiently address mechanisms of heart failure development specifically for these patients. We show that cardiomyocyte cytokinesis failure is increased in tetralogy of Fallot with pulmonary stenosis (ToF/PS), a common form of CHD. Labeling of a ToF/PS baby with isotope-tagged thymidine showed cytokinesis failure after birth. We used single-cell transcriptional profiling to discover that the underlying mechanism is repression of the cytokinesis gene ECT2, and show that this is downstream of $\beta$-adrenergic receptors $(\beta$-AR). Inactivation of the $\beta$-AR genes and administration of the $\beta$-blocker propranolol increased cardiomyocyte division in neonatal mice, which increased the endowment and conferred benefit after myocardial infarction in adults. Propranolol enabled the division of ToF/PS cardiomyocytes. These results suggest that $\beta$-blockers should be evaluated for increasing cardiomyocyte division in patients with ToF/PS and other types of CHD.

\section{INTRODUCTION}

Congenital heart disease (CHD) is the most common birth defect. Improvements in diagnosis and treatment of CHD have increased survival, and 1 million patients live in the US with CHD ${ }^{1}$. Patients with CHD have a high lifetime risk for developing heart failure, and current thinking about this is based on research on heart failure in adult patients ${ }^{1}$. We have considered the possibility that CHD may alter cellular growth of the myocardium, i.e., cardiomyocyte proliferation and differentiation, because these mechanisms are active in infants and children without heart disease ${ }^{2,3}$.

Tetralogy of Fallot with pulmonary stenosis (ToF/PS) is a common form of CHD with relatively uniform structural defects (anterior deviation of the infundibulum, pulmonary stenosis, ventricular septal defect, and right ventricular hypertrophy). Despite extensive progress in understanding the genetic causes of CHD, the majority of ToF/PS remains genetically unexplained ${ }^{4}$. Infants and children with ToF/PS rarely have heart failure, but it is a welldocumented cause of morbidity and mortality in adults ${ }^{5-12}$. Current thinking is that the sequelae of cardiac surgery cause an increased risk of heart failure. However, classical studies showed severe cardiomyocyte changes in ToF/PS patients prior to surgery ${ }^{13}{ }^{14}$, but did not examine cardiomyocyte proliferation and differentiation. This suggested to us that myocardial changes happen before surgery. We have considered this possibility and found changes in cardiomyocyte proliferation and differentiation in ToF/PS.

Recent studies have shown that cardiomyocytes divide in human infants and children in contrast to the extremely low cardiomyocyte division rate in adults ${ }^{2,3,15}$. When cardiomyocytes stop proliferating, they undergo incomplete cell cycles, leading to binucleated cardiomyocytes. Although the mechanisms of formation of binucleated cardiomyocytes are unknown, it is thought that they do not divide further ${ }^{16}$. Mice and rats form binucleated cardiomyocytes in the first week after birth ${ }^{17-19}$. Zebrafish have only mononucleated cardiomyocytes, which can divide and regenerate myocardium ${ }^{20}$, which has led to the hypothesis that a high percentage of mononucleated cardiomyocytes is the foundation for myocardial regeneration. However, humans have $70 \%$ mononucleated cardiomyocytes and yet do not regenerate myocardium. In addition, 
cardiomyocytes differentiate by endocycling, which increases the DNA content of nuclei without nuclear division, i.e., they become polyploid. Humans show a high degree of endocycling around 10 years after birth ${ }^{2,3,15}$. Two recent papers have altered the percentage of binucleated cardiomyocytes in mice and zebrafish, but this resulted in additional large changes of polyploid cardiomyocytes $^{21,22}$. Although multiple studies have suggested that cardiomyocytes become binucleated by incomplete cytokinesis ${ }^{23-25}$, the precise mechanisms and relevance of cardiomyocyte binucleation are still unknown. During cytokinesis, a contractile ring forms at the future division plane ${ }^{26}$. Contraction of this ring is triggered by the cytokinesis protein ECT2, a RhoA guanine-nucleotide exchange factor. RhoA-GTP activates, via Rho-associated protein kinase (ROCK), non-muscle myosin II, which constricts the cleavage furrow.

Different pathways regulate cardiomyocyte proliferation, with the Hippo tumor suppressor pathway taking a central position ${ }^{27}$. The Hippo pathway is regulated by $\mathrm{G}$ protein-coupled receptors (GPCR), and, in the heart, activated by $\beta$-adrenergic receptors $(\beta \text {-AR })^{28}$. $\beta$-AR regulate cardiomyocyte contractile function, by adjusting the intracellular second messenger cyclic adenosine monophosphate (cAMP) ${ }^{29}$. In CHD, and specifically in ToF/PS, $\beta$-AR signaling is overactivated $^{30-34}$. Adrenergic signaling has also been evaluated in the context of heart regeneration in mice ${ }^{35,36}$ and cell cycle activity in cultured rat cardiomyocytes ${ }^{37-39}$; however, these results were obtained without genetic disruption of signaling pathways. Our results extend these findings by demonstrating a function of $\beta$-adrenergic receptors $(\beta$-AR) signaling in regulating cardiomyocyte cytokinesis in vivo.

Using formation of binucleated cardiomyocytes as read-out for the definitive endpoint of cell division, we discovered extensive changes of cardiomyocyte proliferation in ToF/PS. We identified the mechanisms of formation of binucleated cardiomyocytes, establishing a new connection between $\beta$-AR signaling and regulation of cardiomyocyte cytokinesis.

\section{RESULTS}

\section{Infants with Tetralogy of Fallot with pulmonary stenosis have increased binucleated cardiomyocytes}

We examined samples from the right ventricle of patients with ToF/PS and made the surprising observation that the percentage of binucleated cardiomyocytes was increased to $50-60 \%$ (Fig. 1A-C), suggesting extensively increased cytokinesis failure. The temporal pattern of this increase shows that babies with ToF/PS were born with the appropriate percentage of $20 \%$ binucleated cardiomyocytes ${ }^{2,3}$, but that the increase happened in the first 6 months after birth (Fig. 1B). All ToF/PS patients $>2$ months had cardiomyocytes with $>2$ nuclei, a very rare phenotype in humans without heart disease (Fig. 1C), suggesting that multiple serial cytokinesis failures occurred. Bi- and multi-nucleated cardiomyocytes were present in 6 and 13-year-old patients, i.e., after the decline of cardiomyocyte cell cycle activity to the very low levels present in adults. This shows that bi- and multi-nucleated cardiomyocytes generated in the first 6 months after birth live for at least one decade. To directly assess the generation of mono- and binucleated cardiomyocytes, we labeled a 1-month-old ToF/PS baby with ${ }^{15} \mathrm{~N}$-thymidine and examined uptake and retention with multiple-isotope imaging mass spectrometry (MIMS) at 7 months of age (Fig. 1D, E). ${ }^{15} \mathrm{~N}$-thymidine labeling was twice as high in the binucleated cells compared to mononucleated cardiomyocytes (Fig. 1F), indicating extensive cardiomyocyte cytokinesis failure 
corresponding to a $20-30 \%$ reduction of the number of cardiomyocytes (endowment). These findings motivated us to determine the mechanisms controlling cytokinesis in cardiomyocytes.

\section{Cytokinesis failure in cardiomyocytes is associated with low levels of the Rho guanine nucleotide exchange factor Ect2}

To determine the cellular mechanisms of cytokinesis failure in cardiomyocytes, we performed live cell imaging with neonatal rat ventricular cardiomyocytes that undergo binucleation (NRVM, Fig. 2A, Video S1). Cleavage furrow ingression was observed in $80 \%$ of the cardiomyocytes studied, followed by cleavage furrow regression. We used a transgenic mouse model expressing the fluorescent ubiquitination-based cell cycle indicator (FUCCI) to highlight cell cycle progression ${ }^{40}$, which showed normal cell cycle progression until cleavage furrow regression (Videos S2, S3). This finding demonstrates that failure of abscission generates binucleates from mononucleated cardiomyocytes.

To identify the molecular mechanisms of cleavage furrow regression, we separated cycling from non-cycling cardiomyocytes and took a single cell transcriptional profiling approach to compare the expressed genes (Fig. S1). We isolated embryonic (Embryonic day 14.5, E14.5) and neonatal (Postnatal day 5, P5) cardiomyocytes and identified cycling cardiomyocytes with the mAGhGem reporter of the FUCCI indicator ${ }^{40}$ (Fig. S2). We performed deep, genome-wide, single-cell transcriptional analysis with the Eberwine method ${ }^{41-43}$, followed by validation of the results (Fig. S3). Because RhoA activation is required for cleavage furrow constriction, we examined the expression of Dbl-homology Rho-Guanine Nucleotide Exchange Factors (GEF) in the single cell transcriptional dataset (Fig. 2B, Table S1). Ect2 mRNA was present in cycling E14.5 cardiomyocytes but not in binucleating P5 cardiomyocytes (Fig. 2B). Other genes controlling cytokinesis, i.e., Racgapl (inactivating RhoA), RhoA, Anillin, Aurkb, and Mklp1, were present in P5 cycling cardiomyocytes (Fig. S4), indicating that Ect 2 is uniquely regulated. In accordance with the decreased Ect2 levels, active RhoA (RhoA-GTP) was decreased in binucleating cardiomyocytes (Fig. 2C). Taken together, these results show insufficient Ect 2 levels in cardiomyocytes lead to less RhoA activation, weakening their cleavage furrows ${ }^{26}$.

We tested whether increasing Ect 2 expression enables cardiomyocyte abscission by expressing GFP-Ect ${ }^{44}$. Live cell imaging showed the functionality of GFP-ECT2 in cardiomyocytes (Fig. 2D and Video S4) and increased cardiomyocyte abscission (Fig. 2E) without inducing apoptosis (Fig. S6). GFP-Ect2 did not alter cardiomyocyte BrdU uptake (Fig. 2F) or H3P (Fig. 2G). In conclusion, increasing Ect 2 expression in cardiomyocytes has a specific effect on abscission without changing cell cycle entry or progression.

\section{Lowering Ect2 expression reduces cardiomyocyte endowment and heart function}

We next tested the hypothesis that lowering the expression of Ect2 induces cytokinesis failure in vivo. To this end, we inactivated the Ect $2^{\text {flox }}$ gene in mice with $\alpha \mathrm{MHC}-\mathrm{Cr} e^{45}$, (Fig. S6A). $\alpha M H C$-Cre; Ect $2^{f l o x}$ flox mice showed a 3.2-fold increase of binucleated cardiomyocytes (23.3\%, Fig. 2H), compared to $\alpha M H C$-Cre; Ect $2^{\text {wt fflox }}$ mice $(7.4 \%, \mathrm{P}<0.0001)$, at $\mathrm{P} 1$. Ect 2 inactivation did not change the DNA contents of nuclei (Fig. 2I). $\alpha M H C-C r e^{+} ; E c t 2^{\text {flox flox }}$ pups had 583,000 \pm 15,379 cardiomyocytes $(\mathrm{n}=5$ hearts $)$ at $\mathrm{P} 1$, a $49 \%$ decrease compared to $\alpha M H C-C r e^{+} ; E c t 2^{w t / f l o x}$ mice $(1,140,833 \pm 58,341$ cardiomyocytes, $\mathrm{n}=12$ hearts, $\mathrm{P}<0.0001$, Fig. 2J). The mean cardiomyocyte size in $\alpha M H C$-Cre; Ect $2^{f l o x}$ flox mice was increased by $65 \%$ (Fig. 2K). These 
results show that the lower endowment in $\alpha M H C$-Cre;Ect $2^{\text {flox/flox }}$ pups triggered cardiomyocyte hypertrophy, and not a compensatory increase in cell cycling. The heart weight was unchanged

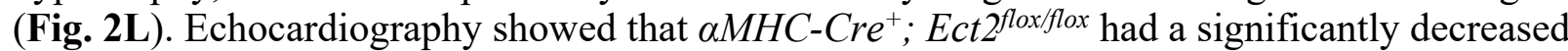
heart function, measured by ejection fraction $(\mathrm{EF}=49.6 \%)$, compared with control $(\mathrm{EF}=85.9 \%$, Fig. 2M, Video S6 and S7). All the $\alpha M H C-C r e^{+}$; Ect $2^{\text {flox fllox }}$ died before P2 (Fig. 2N, S6B). $E c t 2^{f l o x}$ inactivation did not change cardiomyocyte M-phase activity, as measured by quantification of H3P-positive nuclei (Fig. 2O). We observed binucleated Ect $2^{\text {flox/flox }}$ cardiomyocytes with both nuclei being in M-phase, indicating that forcing cytokinesis failure does not prevent entry into another cell cycle and advancement to karyokinesis (Fig. 20). This finding suggests a mechanism for how cardiomyocytes with four and more nuclei are generated, i.e., by serial karyokinesis and failure of abscission. To determine whether Ect2 gene inactivation alters cardiomyocyte cell cycle entry, we inactivated an Ect $2^{\text {flox}} 46$ gene with $\alpha \mathrm{MHC}$ MerCreMer ${ }^{47}$ (tamoxifen P0, 1, 2) in vivo, thus circumventing the lethality of inactivating with $\alpha \mathrm{MHC}-\mathrm{Cre}$. We isolated cardiomyocytes at P2 and cultured for 3 days in the presence of BrdU. Ect2 inactivation did not alter cell cycle entry (Fig. 2P) or cell viability (Fig. S9). In conclusion, Ect2 inactivation induced cytokinesis failure in cardiomyocytes, which decreased endowment by $50 \%$ and led to severely decreased ejection fraction and death.

\section{B-adrenergic receptors control cardiomyocyte abscission and endowment by regulating the Hippo tumor suppressor pathway and Ect2}

We next sought to identify the mechanisms responsible for decreasing transcription of the Ect 2 gene. Previous publications suggested that the Hippo tumor suppressor pathway regulates cardiomyocyte proliferation ${ }^{48-50}$. YAP1, the central transcriptional co-regulator controlled by the Hippo pathway, forms a protein complex with TEAD transcription factors ${ }^{49}$. We identified five binding sites for the transcription factors TEAD 1 and 2 in the Ect 2 promoter (Fig. S7).

Removing these TEAD-binding sites individually or en bloc decreased Ect 2 promoter activity in Luciferase assays (Fig. 3A). siRNA knockdown of TEAD1/2 reduced Ect 2 mRNA levels and increased the proportion of binucleated cardiomyocytes (Fig. 3B-C). Adenoviral-mediated overexpression of wild type YAP1 (YAP1-WT) and a non-degradable version (YAP1-S127A) in NRVMs increased Ect 2 mRNA levels and reduced the proportion of binucleated cardiomyocytes (Fig. 3D-E). These results show that YAP1 and TEAD1/2 regulate the expression of Ect 2 and cardiomyocyte abscission.

The Hippo pathway is activated by G protein coupled receptors (GPCR) via the stimulatory G protein, Gs ${ }^{28}$. Accordingly, we treated cultured NRVMs with forskolin, a mimic of active Gs ${ }^{51}$, which decreased Ect2 mRNA levels (Fig. 3F). We administered forskolin in newborn mice and found a $37 \%$ increase in the proportion of binucleated cardiomyocytes after 4 days and a $21 \%$ increase after 8 days (Fig. 3G). Because $\beta_{1}$ - and $\beta_{2}$-adrenergic receptors $\left(\beta_{1-}, \beta_{2}-A R\right)$ are the major Gs-activating GPCR in cardiomyocytes, we examined $\beta_{1}-\mathrm{AR}^{-/-} ; \beta_{2}-\mathrm{AR}^{-/-}$(doubleknockout, DKO, ${ }^{52,53}$ pups. These mice showed a lower proportion of binucleated cardiomyocytes (Fig. 3H) and a higher endowment at P4 (Fig. 3I). Their cardiomyocyte Mphase activity was not changed (Fig. 3J). $\beta_{1}-\mathrm{AR}^{-/-} ; \beta_{2}-\mathrm{AR}^{-/-} \mathrm{DKO}$ hearts showed increased transcription of the Hippo target genes Cyr61 and $C T G F$, as well as Ect2 (Fig. 3K). We then administered propranolol, a blocker of $\beta_{1}$ - and $\beta_{2}-A R$, in newborn mice. Propranolol decreased the proportion of binucleated cardiomyocytes by $21 \%$ after treatment from P1 to P4, and by $17 \%$ after treatment from P1 to P8 (Fig. 3L). This was associated with a $22 \%$ and $30 \%$ increase of cardiomyocyte endowment at P4 and P8, respectively (Fig. 3M), without a change of 
cardiomyocyte M-phase (Fig. 3N) or heart weight (Fig. 3O). These results show that reducing $\beta$ adrenergic receptor signaling enables abscission, thus increasing the endowment.

\section{Increasing cardiomyocyte endowment by administration of propranolol in neonatal mice improved heart function and reduced adverse remodeling due to myocardial infarction in adulthood}

Although the propranolol-increased cardiomyocyte endowment did not alter cardiac function (Fig. 4A), a larger endowment should confer a benefit after large-scale cardiomyocyte loss, for example, after myocardial infarction (MI). We tested this by administering propranolol in the first week after birth and then inducing myocardial infarction in adult mice (Fig. 4B). We determined cardiac structure and function with MRI and histology (Fig. 4B). Twelve days after MI, mice with propranolol-induced endowment growth had an ejection fraction of $42 \%$, compared with 18\% in control mice (Fig. 4C). The thinned region of the LV myocardium after myocardial infarction was significantly smaller (Fig. 4D), and the relative systolic thickening was higher (Fig. 4E), indicating less adverse remodeling. Importantly, the region of myocardium affected by ischemia, visualized by late Gadolinium enhancement (Fig. 4F), and the scar size, determined by histology (Fig. 4G), were not different. Propranolol-treated hearts had a 30\% higher cardiomyocyte endowment after MI (determined by stereology, Fig. 4H), in keeping with the increased endowment before MI. The heart weight was not changed (Fig. 4I), indicating that the higher endowment reduced the maladaptive hypertrophy, which drives adverse remodeling after MI. Taken together, these results demonstrate that rescuing cardiomyocyte cytokinesis failure with propranolol at the end of development reduces adverse ventricular remodeling in adult mice.

\section{$\beta$-blockers rescue cytokinesis failure in cardiomyocytes from infants with ToF/PS}

We determined if the molecular mechanisms of cardiomyocyte cytokinesis failure we discovered are responsible for the increased proportion of binucleated cardiomyocytes in ToF/PS. To this end, we transcriptionally profiled single cardiomyocytes from infants with ToF/PS. ToF/PS cardiomyocytes showed lower Ect 2 mRNA levels compared with dividing human fetal cardiomyocytes (Fig. 5A). The frequency of Ect2-expressing cycling cardiomyocytes in ToF/PS infants $(24.4 \%)$ was significantly lower than in human fetal cardiomyocytes $(75.6 \%$, Fig. 5B).

Thus, cardiomyocytes in ToF/PS infants exhibit decreased Ect2 levels, similar to cardiomyocytes in neonatal mice (see Fig. 2B). This prompted us to examine the regulation by $\beta$-receptors. We used cultured human fetal cardiomyocytes and added forskolin to maximally increase cardiomyocyte cytokinesis failure (Fig. 5C). We then treated with dobutamine to mimic the in vivo microenvironment of increased $\beta$-AR stimulation, which increased binucleated cardiomyocytes to $95.2 \%$ of the forskolin-induced increase (Fig. 5C). Addition of propranolol blocked the dobutamine-stimulated increase of cardiomyocyte cytokinesis failure completely (Fig. 5C). We examined cardiomyocytes in cytokinesis by immunofluorescence microscopy, which showed that Ect2-positive midbodies were increased with propranolol (Fig. 5D). We then generated organotypic cultures of heart pieces from infants with ToF/PS and added BrdU to label cycling cardiomyocytes (Fig. 5E). Forskolin and dobutamine induced a maximal increase of binucleated cardiomyocytes, and propranolol inhibited the dobutamine-stimulated increase completely (Fig. 5E). In conclusion, $\beta$-receptors regulate cytokinesis failure in cardiomyocytes from infants with ToF/PS and propranolol decreases this effect. 


\section{DISCUSSION}

Our results show that ToF/PS infants develop increased cardiomyocyte terminal differentiation, measured by increased formation of binucleated cardiomyocytes. This happens in the first 6 months after birth, which shows that these changes do not result from surgical or medical interventions. The changes persisted in older ToF/PS patients. The increased binucleation indicates a proportionate failure of cytokinesis, reducing cardiomyocyte proliferation by $25 \%$. By identifying the upstream molecular regulators, we show that $\beta$-blockers could turn cytokinesis failure to increased division.

The results in mice demonstrate that promoting the progression of cytokinesis to abscission in the post-natal period increases the endowment, which improves remodeling due to myocardial infarction. This raises the possibility that a decreased or increased cardiomyocyte endowment connects to outcomes in human patients. This could be tested with $\beta$-blocker administration in human infants with CHD to increase the endowment, followed by measuring clinical outcomes, such as myocardial function and risk of heart failure development. $\beta$-blockers have been used acutely to treat and prevent cyanotic spells in ToF/PS ${ }^{54}$. Although this demonstrates that $\beta$ blockers are safe in this population, an effect on myocardial growth mechanisms was not evaluated. Our results also predict that administration of $\beta$-blockers should produce the largest effect on cardiomyocyte cytokinesis in the first 6 months after birth, which is in line with our previously demonstrated effectiveness of stimulating cardiomyocyte cell cycling in CHD cardiomyocytes in the same period ${ }^{55}$. The duration of this period should also be assessed in types of CHD other than ToF/PS.

Elucidating the mechanisms generating binucleated cardiomyocytes allows us to compare this process in other cell types. Formation of binucleated cells is also an early event in cancer formation, leading, via entrapment of lagging chromosomes in the cleavage furrow, to aneuploidy ${ }^{56}$. In this process, chromosome entrapment lowers Rho A activity in the cleavage furrow, leading to relaxation of the contractile ring and cytokinesis failure. However, we have no evidence for chromatin entrapment cardiomyocyte cytokinesis failure. In cancer cells, cytokinesis failure activates the Hippo tumor suppressor pathway ${ }^{57}$; however, we found that Hippo pathway activation triggers cytokinesis failure in cardiomyocytes. Cytokinesis failure is also a step in platelet formation, also induced by repression of Ect2 ${ }^{58}$. This suggests a generalizable molecular mechanism of Ect 2 repression in cytokinesis failure in somatic cells.

Cardiomyocyte cell cycle withdrawal in mice happens in the first 3 weeks ${ }^{59}$ and formation of binucleated cardiomyocytes in the first 2 weeks after birth ${ }^{18,19}$. This is nearly coincident, which suggests that they could be mechanistically connected. However, we show that by increasing or decreasing cardiomyocyte binucleation, cardiomyocyte cell cycle entry does not change, thus demonstrating that formation of binucleated cardiomyocytes and cell cycle withdrawal are distinct molecular processes. This is supported by the increase of multinucleated cardiomyocytes ( $>2$ nuclei) in ToF/PS, which shows that in ToF/PS, binucleated cardiomyocytes re-enter the cell cycle. This is consistent with the literature demonstrating that pig cardiomyocytes have up to 16 nuclei $^{60}$, which shows that binucleated cardiomyocytes can re-enter the cell cycle multiple times.

Our results place the Hippo pathway downstream of $\beta$-AR signaling and upstream of Ect 2 gene regulation. This does not involve regulation of cell cycle entry and, as such, is distinct from 
direct genetic modulation of the central Hippo kinases and scaffolds, or regulation of the dystroglycan/agrin complex ${ }^{27}$, which all have a significant effect on cell cycle entry. Because of the large number of different G protein coupled receptors (GPCR), it is possible that other GPCR may have a function in regulating cardiomyocyte cell cycle entry, progression, and division.

Low levels of cardiomyocyte proliferation in mammals continue to be a barrier for heart regeneration ${ }^{27}$. To overcome this, molecular interventions to stimulate cardiomyocyte cell cycle entry in adults have been proposed: increase of individual positive cell cycle regulators (cyclins A2 and D2, ${ }^{61,62}$ and combinations ${ }^{63}$ ), removal of negative cell cycle regulators ( $\mathrm{p} 53$, pocket proteins, ${ }^{64,65}$ ), and administration of mitogenic growth factors (FGF, NRG1, Oncostatin M, FSTL1, ${ }^{55,66-68}$ ). All of these approaches involve oncogenes or tumor suppressors and are associated with the risk of inducing uncontrolled proliferation. The findings presented here indicate that targeting the final stage of the cell cycle, i.e., abscission, is a viable strategy that could synergize with any of these interventions to increase cardiomyocyte generation.

\section{Acknowledgments}

We thank Tae Kyung Kim (University of Pennsylvania) for help with initial single cell amplifications. We thank Channing Der (University of North Carolina Chapel Hill) for providing Ect $2^{\text {flox }}$ mice and Mark Petroncski (Clare Hall Laboratories, London), Buzz Baum (University College London), and Toru Miki (Nagaoka University of Technology) for providing Ect2 expression constructs. We thank Maria Magaro (Harvard Medical School) for technical assistance with phenotyping of cardiomyocytes. We thank the patients and families for participating in this research and the operating room staff and cardiac surgeons for assistance with identifying study subjects and ascertaining samples. We thank Sean Lal and Cris dos Remedios (University of Sydney) and Charles McThiernan (University of Pittsburgh) for providing human myocardial samples. This project used the UPMC Hillman Cancer Center and Tissue and Research Pathology/Pitt Biospecimen Core shared resource which is supported in part by award P30CA047904. We thank members of the Kuhn laboratory for support, helpful discussions, and critical reading of the manuscript.

\section{Funding}

This research was supported by the Richard King Mellon Foundation Institute for Pediatric Research (UPMC Children's Hospital of Pittsburgh), by a Transatlantic Network of Excellence grant by Fondation Leducq (15CVD03), Children's Cardiomyopathy Foundation, and NIH grant R01HL106302 (to B.K.) and Health Research Formula Funds from the Commonwealth of Pennsylvania which had no role in study design or interpretation of data (to J.H.E.). This project was supported in part by UPMC Children's Hospital of Pittsburgh (to H.L.), Genomics Discovery Award (to B.K. and D.K.), and UPP Physicians (to B.K.).

\section{Author contributions}

H.L., C.-H.Z., S.S., G.M.U., M.S., and B.K. developed the research strategy.

S.S., G.M.U., M.A., and S.W. developed assays.

H.L., C.-H.Z., S.S., G.M.U., M.A., N.A., B.G., L.H., K.R., N.C., C.L., S.W., Y.W., D.Y., and 
S.C. performed experiments.

S.S., J.S., and S.C. performed transcriptional analysis of single mouse cardiomyocytes, with direct input and supervision by J.H.E.

N.A. performed mouse surgery, stereology, and transcriptional analysis of single human cardiomyocytes.

M.K., J.K., A.B., D.K., J.D., Z.B.-J. performed bioinformatics analysis of single-cell transcriptomes.

K.L., K.F., N.A., and B.K. developed the approach for identification of human study subjects and ascertaining of myocardium.

K.L. and K.F. identified human subjects.

M.S. and M.V. assisted K.L. and K.F. in identification of human study subjects and assisted N.A. in ascertainment of human heart samples.

M.L.S. and B.K. designed the human labeling and MIMS approach; C.G. and M.L.S. performed MIMS analysis.

H.L., C.-H.Z., S.S., G.M.U., M.A., N.A., C.L., and B.K. wrote parts of the manuscript, which B.K. assembled, and all authors edited.

B.K. supervised and coordinated the entire study.

\section{Competing interests}

The authors declare that they have no competing interests.

\section{Data availability}

The datasets generated or analyzed for this study are available from the corresponding author upon request. The single-cell transcriptional profiling data have been deposited in NCBI's Gene Expression Omnibus (GEO) with the dataset identifiers GSE108359 and GSE56638.

\section{Supplementary Materials}

Materials and Methods

Figures S1 - S9

Tables S1 - S8

Captions for Videos S1 - S7

Table S1 (uploaded separately in an excel file)

Videos S1 - S7

References (1-16) 


\section{FIGURE LEGENDS}

Figure 1. Cardiomyocytes in infants with Tetralogy of Fallot with pulmonary stenosis (ToF/PS) fail to divide. (A-C) Patients with Tetralogy of Fallot and pulmonary stenosis (ToF/PS) show an increased proportion of multinucleated $(\geq 2)$ cardiomyocytes (filled symbols and solid lines in $\mathbf{B})$. Each symbol in $(\mathbf{B})$ and bar in $(\mathbf{C})$ represents one human heart (ToF/PS: $\mathrm{n}=$ 12; No heart disease: $\mathrm{n}=5$ ). ( D-F) A 4-week-old infant with ToF/PS was labeled with oral ${ }^{15} \mathrm{~N}$ thymidine. Myocardium was analyzed by multiple-isotope imaging mass spectrometry (MIMS) at 7 months. (D-E) ${ }^{31} \mathrm{P}$ reveals nuclei and ${ }^{32} \mathrm{~S}$ morphologic detail, including striated sarcomeres. Nuclei are dark in the ${ }^{32} \mathrm{~S}$ image. The ${ }^{15} \mathrm{~N} /{ }^{14} \mathrm{~N}$ ratio image reveals ${ }^{15} \mathrm{~N}$-thymidine incorporation. The blue end of the scale is set to natural abundance (no label uptake) and the upper bound of the rainbow scale is set to $50 \%$ above natural abundance. The white arrows in (D) indicate the boundaries of a labelled mononucleated cardiomyocyte and in $(\mathbf{E})$ the nuclei of a binucleated cardiomyocyte. (F) The percentage of labeled binucleated cardiomyocytes is higher than mononucleated cardiomyocytes (Mononucleated cardiomyocytes analyzed: $\mathrm{n}=282 ; 15 \mathrm{~N}+$ mononucleated cardiomyocytes: $n=25$; Binucleated cardiomyocytes analyzed: $n=104$ (208 total nuclei); $15 \mathrm{~N}+$ binucleated cardiomyocytes: $\mathrm{n}=20$ (40 total nuclei)), indicating that this patient experienced extensive cytokinesis failure. Scale bar: $20 \mu \mathrm{m}(\mathbf{A}), 10 \mu \mathrm{m}(\mathbf{D})$.

Figure 2. Ect2 levels regulate cardiomyocyte cytokinesis and Ect2 gene inactivation lowers endowment and is lethal in mice. (A) Live cell imaging of neonatal rat cardiomyocytes (NRVM, P2-P3, 52 cardiomyocytes) shows that cleavage furrow regression precedes formation of binucleated cardiomyocytes, corresponding to Video S1. Cleavage furrow ingression is between 300-335 min, regression at $355 \mathrm{~min}$, and formation of a binucleated cardiomyocyte at 510 min. (B) Transcriptional profiling of single cycling (+) and not cycling (-) cardiomyocytes at embryonic day 14.5 (E14.5) and 5 days after birth (P5) reveals that of 61 Dbl-homology family RhoGEF, Ect2 is significantly repressed in cycling $\mathrm{P} 5$ cardiomyocytes $(\mathrm{P}<0.05)$. (C) Binucleating cardiomyocytes exhibit lower RhoA activity (RhoA-GTP) at the cleavage furrow (E15.4: 59 midbodies; P2: $\mathrm{n}=56$ midbodies). (D-G) NRVM were transduced with Adv-CMVGFP-Ect2. Live cell imaging shows appropriate and dynamic localization of GFP-ECT2 in cycling NRVM (D, corresponding to Video S4), reduced cytokinesis failure and reduced generation of binucleated cardiomyocytes. $(\mathbf{F}, \mathbf{G})$ Overexpression of GFP-Ect2 does not alter cardiomyocyte S- (F, GFP: $\mathrm{n}=407$; GFP-Ect2: $\mathrm{n}=285$ ) or M-phase (G, GFP: $\mathrm{n}=432$; GFPEct2: $n=443)$. $(\mathbf{H}-\mathbf{P})$ Ect2 gene inactivation in the $\alpha \mathrm{MHC}-\mathrm{Cre}$; Ect $2^{\mathrm{F} / \mathrm{F}}$ mice at P1 $(\mathbf{H}-\mathbf{O})$ showed increased binucleated cardiomyocytes $\left(\mathbf{H}, \operatorname{Ect} 2^{\mathrm{F} / \mathrm{wt}} \mathrm{n}=6\right.$, Ect $2^{\mathrm{F} / \mathrm{F}} \mathrm{n}=6$ hearts $)$ without change of DNA content per nucleus (I, Ect $2^{\mathrm{F} / \mathrm{wt}} \mathrm{n}=642$ cardiomyocytes, Ect $2^{\mathrm{F} / \mathrm{F}} \mathrm{n}=647$ cardiomyocytes), and a 50\% lower cardiomyocyte endowment $\left(\mathbf{J}, \operatorname{Ect}^{\mathrm{F} / \mathrm{wt}} \mathrm{n}=12\right.$, Ect2 ${ }^{\mathrm{F} / \mathrm{F}} \mathrm{n}=5$ hearts). The reduced endowment triggers compensatory cardiomyocyte hypertrophy $\left(\mathbf{K}, \mathrm{Ect} 2^{\mathrm{F} / \mathrm{wt}}\right.$ $\mathrm{n}=1,138$ cardiomyocytes from 6 hearts, $\operatorname{Ect}^{\mathrm{F} / \mathrm{F}} \mathrm{n}=1,015$ cardiomyocytes from 6 hearts), without change of heart weight $\left(\mathbf{L}, \operatorname{Ect} 2^{\mathrm{F} / \mathrm{wt}} \mathrm{n}=14, \operatorname{Ect} 2^{\mathrm{F} / \mathrm{F}} \mathrm{n}=6\right.$ hearts$)$. (M, N) The lower cardiomyocyte endowment leads to myocardial dysfunction at P0 (M, left ventricular endocardium outlined in yellow, Ect $2^{\mathrm{wt} / \mathrm{wt}} \mathrm{n}=4, \mathrm{Ect}^{\mathrm{F} / \mathrm{F}} \mathrm{n}=3$ mice$)$ and lethality before $\mathrm{P} 2(\mathbf{N}$, Video S5), but does not alter the $\mathrm{M}$-phase $\left(\mathbf{O}, \operatorname{Ect}_{2}{ }^{\mathrm{F} / \mathrm{wt}} \mathrm{n}=6, \operatorname{Ect}^{\mathrm{F} / \mathrm{F}} \mathrm{n}=6\right.$ hearts$)$ and cell cycle entry (P, BrdU uptake, Ect $2^{\text {flox }}$ gene inactivation with $\alpha$ MHC-MerCreMer, tamoxifen DOL 0, 1, 2 , followed by 3 days culture). Statistical significance was tested with Student's $t$ - test if not specified, and Fisher's exact test (N). Scale bars $30 \mu \mathrm{m}(\mathbf{E}, \mathbf{P}), 50 \mu \mathrm{m}(\mathbf{F}, \mathbf{G}), 100 \mu \mathrm{m}(\mathbf{K})$. 
Figure 3. $\beta$-adrenergic receptor signaling regulates cardiomyocyte abscission and endowment in mice. (A) Removal of the five TEAD1/2-binding sites (Fig. S7) reduced the activity of the Ect 2 promoter in luciferase assays in HEK293 cells. WT: wild type Ect 2 promoter; $\Delta 1-5$ : All five putative TEAD-binding sites were removed; $\Delta 2 \mathrm{kB}$ : the continuous $2 \mathrm{kB}$ DNA sequence containing all five TEAD-binding sites was removed; Vector: Empty vector that did not contain Ect 2 promoter $(n=4$ cultures $)$. $(\mathbf{B}, \mathbf{C})$ Knockdown of TEAD1 and TEAD2 by siRNA reduced Ect 2 mRNA (B), and increased the proportion of binucleated NRVMs (P2, $\mathbf{C}, \mathrm{n}$ $=3$ cardiomyocyte isolations). (D-E) Adenoviral overexpression of wild type YAP1 (YAP1-WT) and a mutated version containing a S127A mutation (YAP1-S127A) in NRVMs (P2) increased the level of Ect 2 mRNA (D) and reduced the percentage of binucleated cardiomyocytes $(\mathbf{E}, \mathrm{n}=4$ cardiomyocyte isolations). (F) Forskolin reduced the mRNA level of Ect2 in cultured NRVMs (n $=5$ cardiomyocyte isolations $)$. (G) Forskolin administration $(1 \mu \mathrm{g} / \mathrm{g}, 1$ i.p. injection per day) increased the proportion of binucleated cardiomyocytes in vivo $(\mathrm{n}=6$ hearts/group). (H-K) Inactivation of $\beta_{1}$ - and $\beta_{2}$-adrenergic receptor genes (DKO) decreased formation of multinucleated cardiomyocytes in vivo $(\mathbf{H}, \mathrm{n}=4$ hearts/group), increased the total number of cardiomyocytes $(\mathbf{I}, \mathrm{n}=7$ hearts for wild, $\mathrm{n}=5$ hearts for DKO), did not change M-phase $(\mathbf{J}, \mathrm{n}=$ 4 hearts/group), and increased the expression of the YAP target genes Cyr61 and CTGF (K, $\mathrm{n}=$ 3 hearts/group). (L-O) Propranolol administration $(10 \mu \mathrm{g} / \mathrm{g}, 2$ i.p. injections per day) reduced the proportion of multinucleated cardiomyocytes $(\mathrm{L}, \mathrm{n}=6$ hearts/group), and increased the number of cardiomyocytes (M, $\mathrm{n}=6$ heart/group for P4, $\mathrm{n}=4$ hearts/group for P8), but did not alter Mphase activity $(\mathbf{N}, \mathrm{n}=4$ hearts/group) or heart-body-weight ratio $(\mathbf{O}, \mathrm{P} 4: \mathrm{n}=7$ hearts for PBS, $\mathrm{n}$ $=6$ hearts for Prop; P8: $\mathrm{n}=4$ hearts/group). Scale bar: $20 \mu \mathrm{m}(\mathbf{C}, \mathbf{E}, \mathbf{G}, \mathbf{H}, \mathbf{J}, \mathbf{L})$. Statistical significance was tested with one-way ANOVA with Bonferroni's multiple comparisons (A-E), Student's $t$ - test (F, H-K), and two-way ANOVA with Bonferroni's multiple comparisons test (G, L-O).

Figure 4. Mice with a 30\%-increased cardiomyocyte endowment have better cardiac function and reduced adverse remodeling after myocardial infarction (MI). Mice received propranolol (Prop, $10 \mu \mathrm{g} / \mathrm{g}, 2$ i.p. injections per day, P1-12). (A) The ejection fraction (EF) at P60 was not changed ( $n=11$ hearts for PBS, $n=6$ hearts for Prop). (B) Diagram of experimental design. MI was induced at P60 and MRI and histology were performed 12 days after MI. (C) After MI, EF was higher in propranolol-primed mice. (D-G) The region of stretched-out myocardial wall is significantly smaller (D) and systolic myocardial thickening is greater (E), despite same scar size measured in vivo $(\mathbf{F})$ and ex vivo $(\mathbf{G}, \mathrm{n}=5$ hearts for PBS, $\mathrm{n}=4$ hearts for Prop). (H, I) Propranolol-primed hearts show a higher number of cardiomyocytes, determined by stereology ( $n=5$ hearts/group), after MI without change of heart weight $(n=5$ hearts for PBS, $\mathrm{n}=6$ hearts for Prop) (I). Statistical significance was tested with $t$-test.

Figure 5. $\beta$-adrenergic signaling regulates cytokinesis in cardiomyocytes from ToF/PS patients. (A) Cardiomyocytes from ToF/PS patients exhibit decreased levels of Ect2 mRNA. Each symbol represents one cycling cardiomyocyte. (B) The percentage of Ect2-positive cycling cardiomyocytes was reduced in ToF/PS patients, compared with fetal human hearts. (A-B, Fetal: $n=71$ cardiomyocytes from 4 hearts, ToF/PS: $n=13$ cardiomyocytes from 3 hearts). (C, D) $\beta$ AR signaling regulates cytokinesis failure in cultured human fetal cardiomyocytes $(\mathrm{n}=$ isolations from 3 hearts; Ctrl: control; Fsk: Forskolin, Prop: Propranolol; Dobu: Dobutamine: $10 \mu \mathrm{M}$ ), measured by reduced formation of binucleated daughter cells $(\mathbf{C})$ and higher prevalence of Ect2positive midbodies (D). (E) Propranolol increases completion of cytokinesis in cultured ToF/PS cardiomyocytes $(\mathrm{n}=$ cultures from 3 patients). (F) Cellular model connecting cytokinesis failure 
to endowment changes. (G) Molecular model of cytokinesis failure in cardiomyocytes. Scale bar: $40 \mu \mathrm{m}(\mathbf{C})$. Statistical significance was tested with T-test (A) and one-way ANOVA with Bonferroni's multiple comparisons test (C-E).

\section{REFERENCES}

1. Burns KM, Byrne BJ, Gelb BD, Kuhn B, Leinwand LA, Mital S, Pearson GD, Rodefeld M, Rossano JW, Stauffer BL, Taylor MD, Towbin JA and Redington AN. New mechanistic and therapeutic targets for pediatric heart failure: report from a National Heart, Lung, and Blood Institute Working Group. Circulation. 2014;130:79-86.

2. Mollova M, Bersell K, Walsh S, Savla J, Das LT, Park SY, Silberstein LE, Dos Remedios CG, Graham D, Colan S and Kuhn B. Cardiomyocyte proliferation contributes to heart growth in young humans. Proceedings of the National Academy of Sciences of the United States of America. 2013;110:1446-51.

3. Bergmann O, Zdunek S, Felker A, Salehpour M, Alkass K, Bernard S, Sjostrom SL, Szewczykowska M, Jackowska T, Dos Remedios C, Malm T, Andra M, Jashari R, Nyengaard JR, Possnert G, Jovinge S, Druid H and Frisen J. Dynamics of Cell Generation and Turnover in the Human Heart. Cell. 2015;161:1566-75.

4. Fahed AC, Gelb BD, Seidman JG and Seidman CE. Genetics of congenital heart disease: the glass half empty. Circ Res. 2013;112:707-20.

5. Murphy JG, Gersh BJ, Mair DD, Fuster V, McGoon MD, Ilstrup DM, McGoon DC, Kirklin JW and Danielson GK. Long-term outcome in patients undergoing surgical repair of tetralogy of Fallot. N Engl J Med. 1993;329:593-9.

6. Nollert G, Fischlein T, Bouterwek S, Bohmer C, Klinner W and Reichart B. Long-term survival in patients with repair of tetralogy of Fallot: 36-year follow-up of 490 survivors of the first year after surgical repair. J Am Coll Cardiol. 1997;30:1374-83.

7. Nollert G, Fischlein T, Bouterwek S, Bohmer C, Dewald O, Kreuzer E, Welz A, Netz H, Klinner $\mathrm{W}$ and Reichart B. Long-term results of total repair of tetralogy of Fallot in adulthood: 35 years follow-up in 104 patients corrected at the age of 18 or older. Thorac Cardiovasc Surg. 1997;45:178-81.

8. Gatzoulis MA, Balaji S, Webber SA, Siu SC, Hokanson JS, Poile C, Rosenthal M, Nakazawa M, Moller JH, Gillette PC, Webb GD and Redington AN. Risk factors for arrhythmia and sudden cardiac death late after repair of tetralogy of Fallot: a multicentre study. Lancet. 2000;356:975-81.

9. Bacha EA, Scheule AM, Zurakowski D, Erickson LC, Hung J, Lang P, Mayer JE, Jr., del Nido PJ and Jonas RA. Long-term results after early primary repair of tetralogy of Fallot. J Thorac Cardiovasc Surg. 2001;122:154-61.

10. Therrien J, Marx GR and Gatzoulis MA. Late problems in tetralogy of Fallot-recognition, management, and prevention. Cardiol Clin. 2002;20:395-404.

11. D'Andrea A, Caso P, Sarubbi B, Russo MG, Ascione L, Scherillo M, Cobrufo M and Calabro R. Right ventricular myocardial dysfunction in adult patients late after repair of tetralogy of fallot. Int J Cardiol. 2004;94:213-20.

12. Geva T, Sandweiss BM, Gauvreau K, Lock JE and Powell AJ. Factors associated with impaired clinical status in long-term survivors of tetralogy of Fallot repair evaluated by magnetic resonance imaging. J Am Coll Cardiol. 2004;43:1068-74. 
13. Jones M, Ferrans VJ, Morrow AG and Roberts WC. Ultrastructure of crista supraventricularis muscle in patients with congenital heart diseases associated with right ventricular outflow tract obstruction. Circulation. 1975;51:39-67.

14. Jones $\mathrm{M}$ and Ferrans VJ. Myocardial degeneration in congenital heart disease. Comparison of morphologic findings in young and old patients with congenital heart disease associated with muscular obstruction to right ventricular outflow. Am J Cardiol. 1977;39:1051-63.

15. Bergmann O, Bhardwaj RD, Bernard S, Zdunek S, Barnabe-Heider F, Walsh S, Zupicich J, Alkass K, Buchholz BA, Druid H, Jovinge S and Frisen J. Evidence for cardiomyocyte renewal in humans. Science. 2009;324:98-102.

16. Bersell K, Arab S, Haring B and Kuhn B. Neuregulin1/ErbB4 signaling induces cardiomyocyte proliferation and repair of heart injury. Cell. 2009;138:257-70.

17. Li F, Wang X, Capasso JM and Gerdes AM. Rapid transition of cardiac myocytes from hyperplasia to hypertrophy during postnatal development. J Mol Cell Cardiol. 1996;28:1737-46.

18. Soonpaa MH, Kim KK, Pajak L, Franklin M and Field LJ. Cardiomyocyte DNA synthesis and binucleation during murine development. Am J Physiol. 1996;271:H21839.

19. Alkass K, Panula J, Westman M, Wu TD, Guerquin-Kern JL and Bergmann O. No Evidence for Cardiomyocyte Number Expansion in Preadolescent Mice. Cell. 2015;163:1026-36.

20. Wills AA, Holdway JE, Major RJ and Poss KD. Regulated addition of new myocardial and epicardial cells fosters homeostatic cardiac growth and maintenance in adult zebrafish. Development. 2008;135:183-92.

21. Patterson M, Barske L, Van Handel B, Rau CD, Gan P, Sharma A, Parikh S, Denholtz M, Huang Y, Yamaguchi Y, Shen H, Allayee H, Crump JG, Force TI, Lien CL, Makita T, Lusis AJ, Kumar SR and Sucov HM. Frequency of mononuclear diploid cardiomyocytes underlies natural variation in heart regeneration. Nat Genet. 2017;49:1346-1353.

22. Gonzalez-Rosa JM, Sharpe M, Field D, Soonpaa MH, Field LJ, Burns CE and Burns CG. Myocardial Polyploidization Creates a Barrier to Heart Regeneration in Zebrafish. Dev Cell. 2018;44:433-446 e 7.

23. Hesse M, Doengi M, Becker A, Kimura K, Voeltz N, Stein V and Fleischmann BK. Midbody Positioning and Distance Between Daughter Nuclei Enable Unequivocal Identification of Cardiomyocyte Cell Division in Mice. Circ Res. 2018;123:1039-1052.

24. Engel FB, Schebesta M and Keating MT. Anillin localization defect in cardiomyocyte binucleation. J Mol Cell Cardiol. 2006;41:601-12.

25. Leone M, Musa G and Engel FB. Cardiomyocyte binucleation is associated with aberrant mitotic microtubule distribution, mislocalization of RhoA and IQGAP3, as well as defective actomyosin ring anchorage and cleavage furrow ingression. Cardiovasc Res. 2018;114:1115-1131.

26. Fededa JP and Gerlich DW. Molecular control of animal cell cytokinesis. Nat Cell Biol. 2012;14:440-7.

27. Tzahor E and Poss KD. Cardiac regeneration strategies: Staying young at heart. Science. 2017;356:1035-1039.

28. Yu FX, Zhao B, Panupinthu N, Jewell JL, Lian I, Wang LH, Zhao J, Yuan H, Tumaneng K, Li H, Fu XD, Mills GB and Guan KL. Regulation of the Hippo-YAP pathway by Gprotein-coupled receptor signaling. Cell. 2012;150:780-91. 
29. Lohse MJ, Engelhardt S and Eschenhagen T. What is the role of beta-adrenergic signaling in heart failure? Circ Res. 2003;93:896-906.

30. Ross RD, Daniels SR, Schwartz DC, Hannon DW, Shukla R and Kaplan S. Plasma norepinephrine levels in infants and children with congestive heart failure. Am J Cardiol. 1987;59:911-4.

31. Miyamoto SD, Stauffer BL, Polk J, Medway A, Friedrich M, Haubold K, Peterson V, Nunley K, Nelson P, Sobus R, Stenmark KR and Sucharov CC. Gene expression and beta-adrenergic signaling are altered in hypoplastic left heart syndrome. J Heart Lung Transplant. 2014;33:785-93.

32. Miyamoto SD, Stauffer BL, Nakano S, Sobus R, Nunley K, Nelson P and Sucharov CC. Beta-adrenergic adaptation in paediatric idiopathic dilated cardiomyopathy. Eur Heart J. 2014;35:33-41.

33. Medina E, Sucharov CC, Nelson P, Miyamoto SD and Stauffer BL. Molecular Changes in Children with Heart Failure Undergoing Left Ventricular Assist Device Therapy. $J$ Pediatr. 2016.

34. Nakano SJ, Sucharov J, van Dusen R, Cecil M, Nunley K, Wickers S, Karimpur-Fard A, Stauffer BL, Miyamoto SD and Sucharov CC. Cardiac Adenylyl Cyclase and Phosphodiesterase Expression Profiles Vary by Age, Disease, and Chronic Phosphodiesterase Inhibitor Treatment. J Card Fail. 2017;23:72-80.

35. Mahmoud AI, O'Meara CC, Gemberling M, Zhao L, Bryant DM, Zheng R, Gannon JB, Cai L, Choi WY, Egnaczyk GF, Burns CE, Burns CG, MacRae CA, Poss KD and Lee RT. Nerves Regulate Cardiomyocyte Proliferation and Heart Regeneration. Dev Cell. 2015;34:387-99.

36. White IA, Gordon J, Balkan W and Hare JM. Sympathetic Reinnervation Is Required for Mammalian Cardiac Regeneration. Circ Res. 2015;117:990-4.

37. Feridooni T, Hotchkiss A, Baguma-Nibasheka M, Zhang F, Allen B, Chinni S and Pasumarthi KBS. Effects of beta-adrenergic receptor drugs on embryonic ventricular cell proliferation and differentiation and their impact on donor cell transplantation. Am J Physiol Heart Circ Physiol. 2017;312:H919-H931.

38. Kreipke RE and Birren SJ. Innervating sympathetic neurons regulate heart size and the timing of cardiomyocyte cell cycle withdrawal. J Physiol. 2015;593:5057-73.

39. Tseng YT, Kopel R, Stabila JP, McGonnigal BG, Nguyen TT, Gruppuso PA and Padbury JF. Beta-adrenergic receptors (betaAR) regulate cardiomyocyte proliferation during early postnatal life. FASEB J. 2001;15:1921-6.

40. Sakaue-Sawano A, Kurokawa H, Morimura T, Hanyu A, Hama H, Osawa H, Kashiwagi S, Fukami K, Miyata T, Miyoshi H, Imamura T, Ogawa M, Masai H and Miyawaki A. Visualizing spatiotemporal dynamics of multicellular cell-cycle progression. Cell. 2008;132:487-98.

41. Eberwine J and Crino P. Analysis of mRNA populations from single live and fixed cells of the central nervous system. Curr Protoc Neurosci. 2001; Chapter 5:Unit 53.

42. Morris J, Singh JM and Eberwine JH. Transcriptome analysis of single cells. J Vis Exp. 2011.

43. Dueck H, Khaladkar M, Kim TK, Spaethling JM, Francis C, Suresh S, Fisher SA, Seale P, Beck SG, Bartfai T, Kuhn B, Eberwine J and Kim J. Deep sequencing reveals celltype-specific patterns of single-cell transcriptome variation. Genome Biol. 2015;16:122.

44. Su KC, Takaki T and Petronczki M. Targeting of the RhoGEF Ect2 to the equatorial membrane controls cleavage furrow formation during cytokinesis. Dev Cell. 2011;21:1104-15. 
45. Agah R, Frenkel PA, French BA, Michael LH, Overbeek PA and Schneider MD. Gene recombination in postmitotic cells. Targeted expression of Cre recombinase provokes cardiac-restricted, site-specific rearrangement in adult ventricular muscle in vivo. $J$ Clin Invest. 1997; 100:169-79.

46. Cook DR, Solski PA, Bultman SJ, Kauselmann G, Schoor M, Kuehn R, Friedman LS, Cowley DO, Van Dyke T, Yeh JJ, Johnson L and Der CJ. The ect2 rho Guanine nucleotide exchange factor is essential for early mouse development and normal cell cytokinesis and migration. Genes Cancer. 2011;2:932-42.

47. Sohal DS, Nghiem M, Crackower MA, Witt SA, Kimball TR, Tymitz KM, Penninger JM and Molkentin JD. Temporally regulated and tissue-specific gene manipulations in the adult and embryonic heart using a tamoxifen-inducible Cre protein. Circ Res. 2001;89:20-5.

48. Heallen T, Zhang M, Wang J, Bonilla-Claudio M, Klysik E, Johnson RL and Martin JF. Hippo pathway inhibits Wnt signaling to restrain cardiomyocyte proliferation and heart size. Science. 2011;332:458-61.

49. von Gise A, Lin Z, Schlegelmilch K, Honor LB, Pan GM, Buck JN, Ma Q, Ishiwata T, Zhou B, Camargo FD and Pu WT. YAP1, the nuclear target of Hippo signaling, stimulates heart growth through cardiomyocyte proliferation but not hypertrophy. Proc Natl Acad Sci U S A. 2012;109:2394-9.

50. Bassat E, Mutlak YE, Genzelinakh A, Shadrin IY, Baruch Umansky K, Yifa O, Kain D, Rajchman D, Leach J, Riabov Bassat D, Udi Y, Sarig R, Sagi I, Martin JF, Bursac N, Cohen $\mathrm{S}$ and Tzahor E. The extracellular matrix protein agrin promotes heart regeneration in mice. Nature. 2017;547:179-184.

51. Dessauer CW, Watts VJ, Ostrom RS, Conti M, Dove S and Seifert R. International Union of Basic and Clinical Pharmacology. CI. Structures and Small Molecule Modulators of Mammalian Adenylyl Cyclases. Pharmacol Rev. 2017;69:93-139.

52. Rohrer DK, Desai KH, Jasper JR, Stevens ME, Regula DP, Jr., Barsh GS, Bernstein D and Kobilka BK. Targeted disruption of the mouse betal-adrenergic receptor gene: developmental and cardiovascular effects. Proc Natl Acad Sci U S A. 1996;93:7375-80.

53. Chruscinski AJ, Rohrer DK, Schauble E, Desai KH, Bernstein D and Kobilka BK. Targeted disruption of the beta2 adrenergic receptor gene. J Biol Chem. 1999;274:16694700.

54. Barazzone C, Jaccard C, Berner M, Dayer P, Rouge JC, Oberhansli I and Friedli B. Propranolol treatment in children with tetralogy of Fallot alters the response to isoprenaline after surgical repair. Br Heart J. 1988;60:156-61.

55. Polizzotti BD, Ganapathy B, Walsh S, Choudhury S, Ammanamanchi N, Bennett DG, Dos Remedios CG, Haubner BJ, Penninger JM and Kuhn B. Neuregulin stimulation of cardiomyocyte regeneration in mice and human myocardium reveals a therapeutic window. Sci Transl Med. 2015;7:281ra45.

56. Ganem NJ, Storchova Z and Pellman D. Tetraploidy, aneuploidy and cancer. Curr Opin Genet Dev. 2007; 17:157-62.

57. Ganem NJ, Cornils H, Chiu SY, O'Rourke KP, Arnaud J, Yimlamai D, Thery M, Camargo FD and Pellman D. Cytokinesis failure triggers hippo tumor suppressor pathway activation. Cell. 2014;158:833-48.

58. Gao Y, Smith E, Ker E, Campbell P, Cheng EC, Zou S, Lin S, Wang L, Halene S and Krause DS. Role of RhoA-specific guanine exchange factors in regulation of endomitosis in megakaryocytes. Dev Cell. 2012;22:573-84. 
59. Walsh S, Ponten A, Fleischmann BK and Jovinge S. Cardiomyocyte cell cycle control and growth estimation in vivo--an analysis based on cardiomyocyte nuclei. Cardiovasc Res. 2010;86:365-73.

60. Grabner W and Pfitzer P. Number of nuclei in isolated myocardial cells of pigs. Virchows Arch B Cell Pathol. 1974;15:279-94.

61. Shapiro SD, Ranjan AK, Kawase Y, Cheng RK, Kara RJ, Bhattacharya R, GuzmanMartinez G, Sanz J, Garcia MJ and Chaudhry HW. Cyclin A2 induces cardiac regeneration after myocardial infarction through cytokinesis of adult cardiomyocytes. Sci Transl Med. 2014;6:224ra27.

62. Pasumarthi KB, Nakajima H, Nakajima HO, Soonpaa MH and Field LJ. Targeted expression of cyclin D2 results in cardiomyocyte DNA synthesis and infarct regression in transgenic mice. Circ Res. 2005;96:110-8.

63. Mohamed TMA, Ang YS, Radzinsky E, Zhou P, Huang Y, Elfenbein A, Foley A, Magnitsky S and Srivastava D. Regulation of Cell Cycle to Stimulate Adult Cardiomyocyte Proliferation and Cardiac Regeneration. Cell. 2018;173:104-116 e12.

64. Nakajima H, Nakajima HO, Tsai SC and Field LJ. Expression of mutant p193 and p53 permits cardiomyocyte cell cycle reentry after myocardial infarction in transgenic mice. Circ Res. 2004;94:1606-14.

65. MacLellan WR, Garcia A, Oh H, Frenkel P, Jordan MC, Roos KP and Schneider MD. Overlapping roles of pocket proteins in the myocardium are unmasked by germ line deletion of p130 plus heart-specific deletion of Rb. Mol Cell Biol. 2005;25:2486-97.

66. Wei K, Serpooshan V, Hurtado C, Diez-Cunado M, Zhao M, Maruyama S, Zhu W, Fajardo G, Noseda M, Nakamura K, Tian X, Liu Q, Wang A, Matsuura Y, Bushway P, Cai W, Savchenko A, Mahmoudi M, Schneider MD, van den Hoff MJ, Butte MJ, Yang PC, Walsh K, Zhou B, Bernstein D, Mercola M and Ruiz-Lozano P. Epicardial FSTL1 reconstitution regenerates the adult mammalian heart. Nature. 2015;525:479-85.

67. Kubin T, Poling J, Kostin S, Gajawada P, Hein S, Rees W, Wietelmann A, Tanaka M, Lorchner H, Schimanski S, Szibor M, Warnecke H and Braun T. Oncostatin M is a major mediator of cardiomyocyte dedifferentiation and remodeling. Cell Stem Cell. 2011;9:42032.

68. Engel FB, Hsieh PC, Lee RT and Keating MT. FGF1/p38 MAP kinase inhibitor therapy induces cardiomyocyte mitosis, reduces scarring, and rescues function after myocardial infarction. Proc Natl Acad Sci U S A. 2006;103:15546-51. 
A

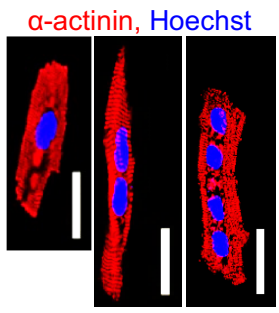

B

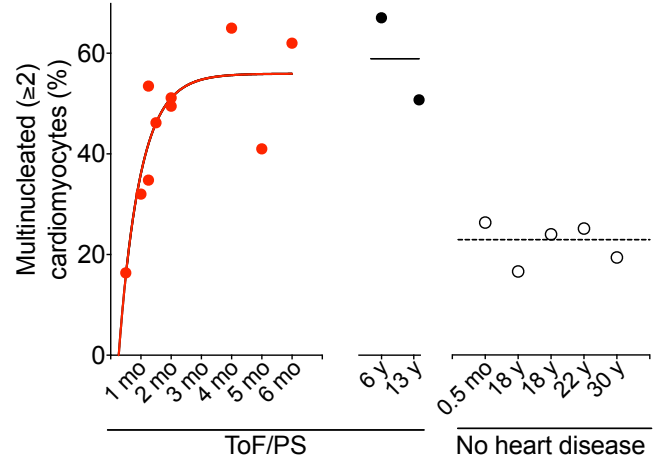

C

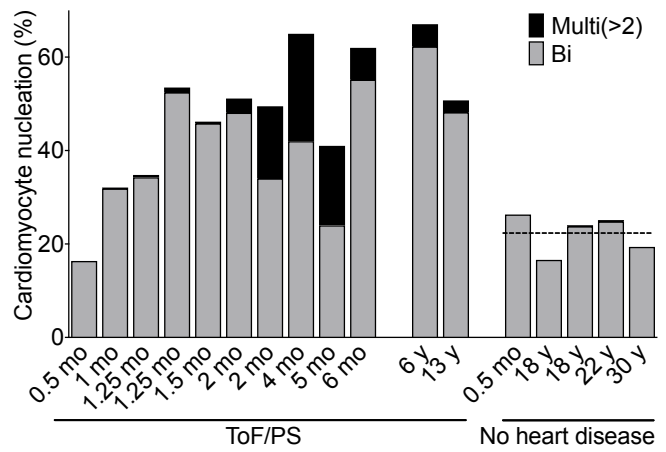

D ${ }^{14} \mathrm{~N}$

${ }^{31} \mathrm{P}$

${ }^{32} \mathrm{~S}$ ${ }^{15} \mathrm{~N}$ thymidine
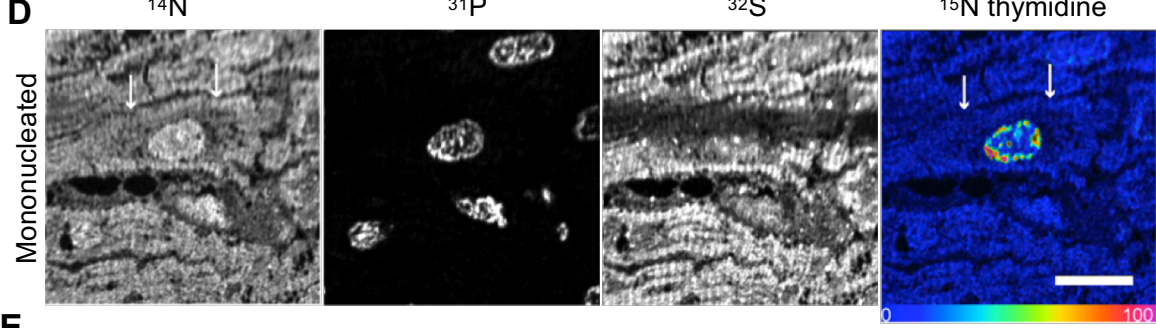

E
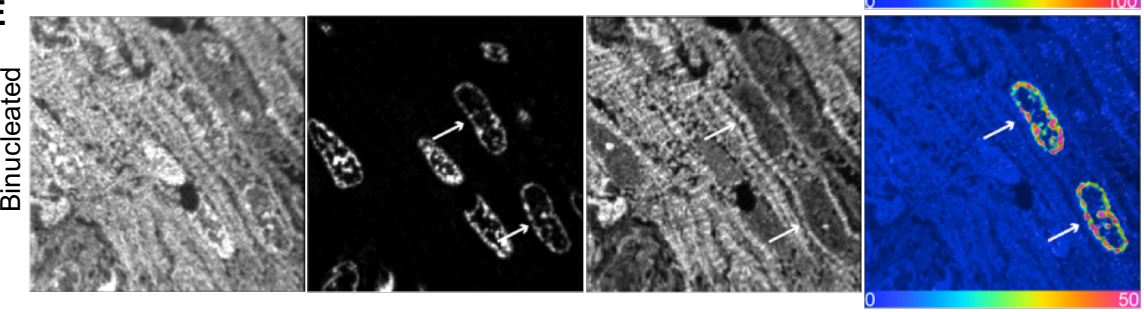

F

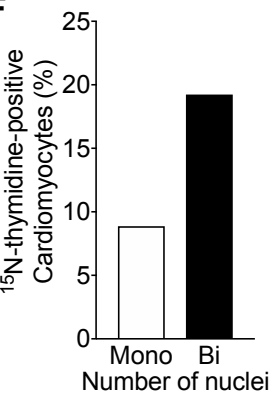

Figure 1. Cardiomyocytes in infants with Tetralogy of Fallot with pulmonary stenosis (ToF/PS) fail to divide. (A-C) Patients with Tetralogy of Fallot and pulmonary stenosis (ToF/PS) show an increased proportion of multinucleated ( $\geq 2)$ cardiomyocytes (filled symbols and solid lines in B). Each symbol in (B) and bar in (C) represents one human heart (ToF/PS: $n=12$; No heart disease: $n=5$ ). (D-F) A 4 week-old infant with ToF/PS was labeled with oral ${ }^{15} \mathrm{~N}$ thymidine. Myocardium was analyzed by multiple-isotope imaging mass spectrometry (MIMS) at 7 months. (D-E) ${ }^{31} \mathrm{P}$ reveals nuclei and ${ }^{32} \mathrm{~S}$ morphologic detail, including striated sarcomeres. Nuclei are dark in the ${ }^{32} \mathrm{~S}$ image. The ${ }^{15} \mathrm{~N} / 14 \mathrm{~N}$ ratio image reveals ${ }^{15} \mathrm{~N}$-thymidine incorporation. The blue end of the scale is set to natural abundance (no label uptake) and the upper bound of the rainbow scale is set to $50 \%$ above natural abundance. The white arrows in (D) indicate the boundaries of a labelled mononucleated cardiomyocyte and in (E) the nuclei of a binucleated cardiomyocyte. (F) The percentage of labeled binucleated cardiomyocytes is higher than mononucleated cardiomyocytes (Mononucleated cardiomyocytes analyzed: $n=282 ; 15 \mathrm{~N}+$ mononucleated cardiomyocytes: $n=25$; Binucleated cardiomyocytes analyzed: $n=104$ (208 total nuclei); $15 N+$ binucleated cardiomyocytes: $n=20$ (40 total nuclei)), indicating that this patient experienced extensive cytokinesis failure. Scale bar: $20 \mu \mathrm{m}$ (A), $10 \mu \mathrm{m}$ (D). 
A

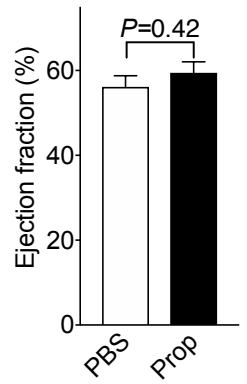

C

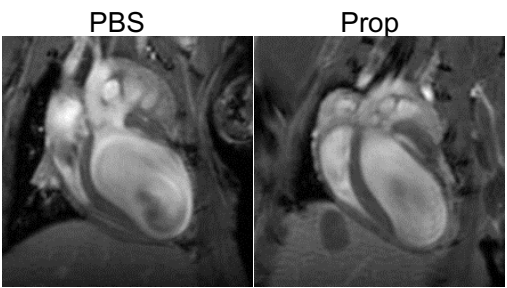

D

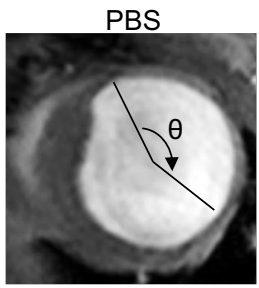

E

E

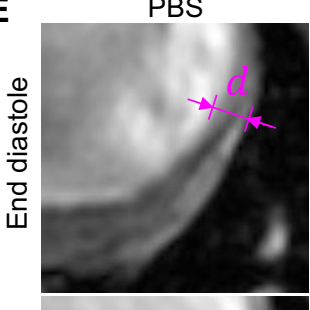

PBS

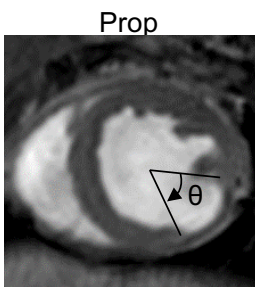

$\frac{0}{\frac{0}{0}}$

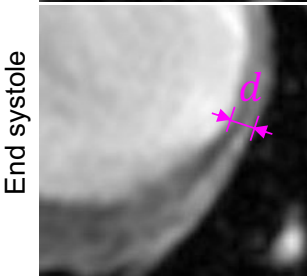

Prop
B

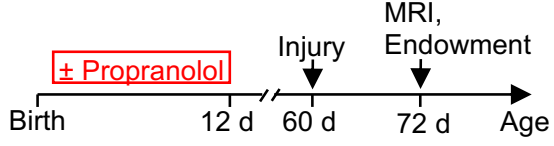

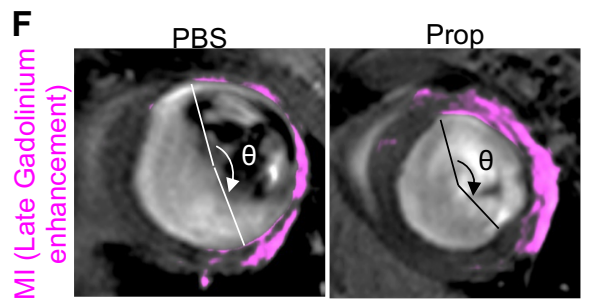
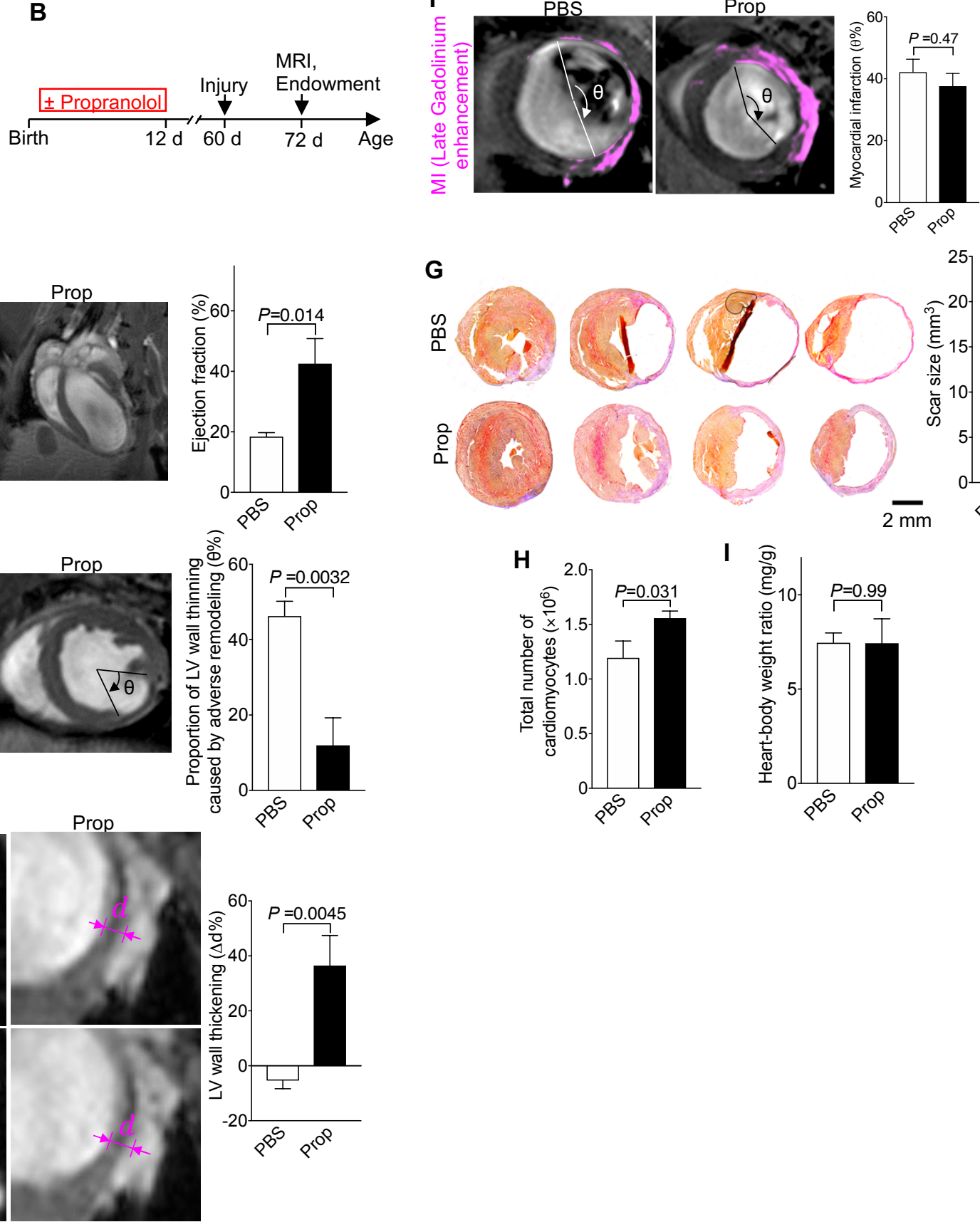

G

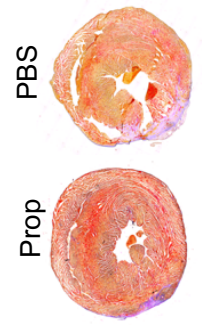

H

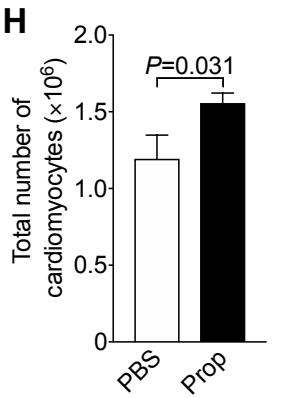

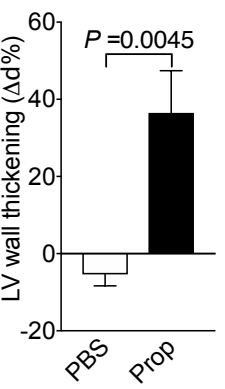

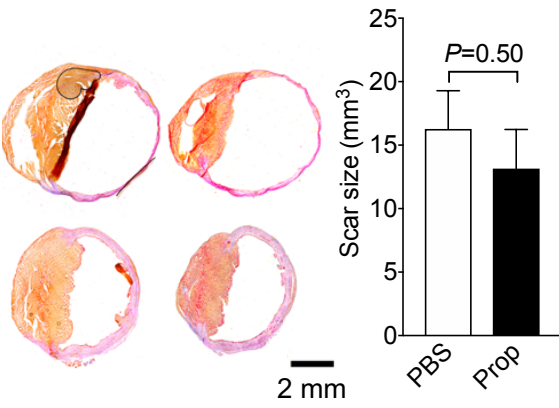

I

Figure 4. Mice with a $30 \%$-increased cardiomyocyte endowment have better cardiac function and reduced adverse remodeling after myocardial infarction (MI). Mice received propranolol (Prop, $10 \mu \mathrm{g} / \mathrm{g}, 2$ i.p. injections per day, P1-12). (A) The ejection fraction (EF) at P60 was not changed ( $\mathrm{n}=11$ hearts for PBS, $n=6$ hearts for Prop). (B) Diagram of experimental design. MI was induced at P60 and MRI and histology were performed 12 days after MI. (C) After MI, EF was higher in propranolol-primed mice. (D-G) The region of stretched-out myocardial wall is significantly smaller (D) and systolic myocardial thickening is greater $(\mathbf{E})$, despite same scar size measured in vivo (F) and ex vivo (G, $n=5$ hearts for PBS, $n=4$ hearts for Prop). (H, I) Propranolol-primed hearts show a higher number of cardiomyocytes, determined by stereology ( $n=5$ hearts/group), after Ml, without change of heart weight $(n=5$ hearts for PBS, $n=6$ hearts for Prop) (I). Statistical significance was tested with t-test. 

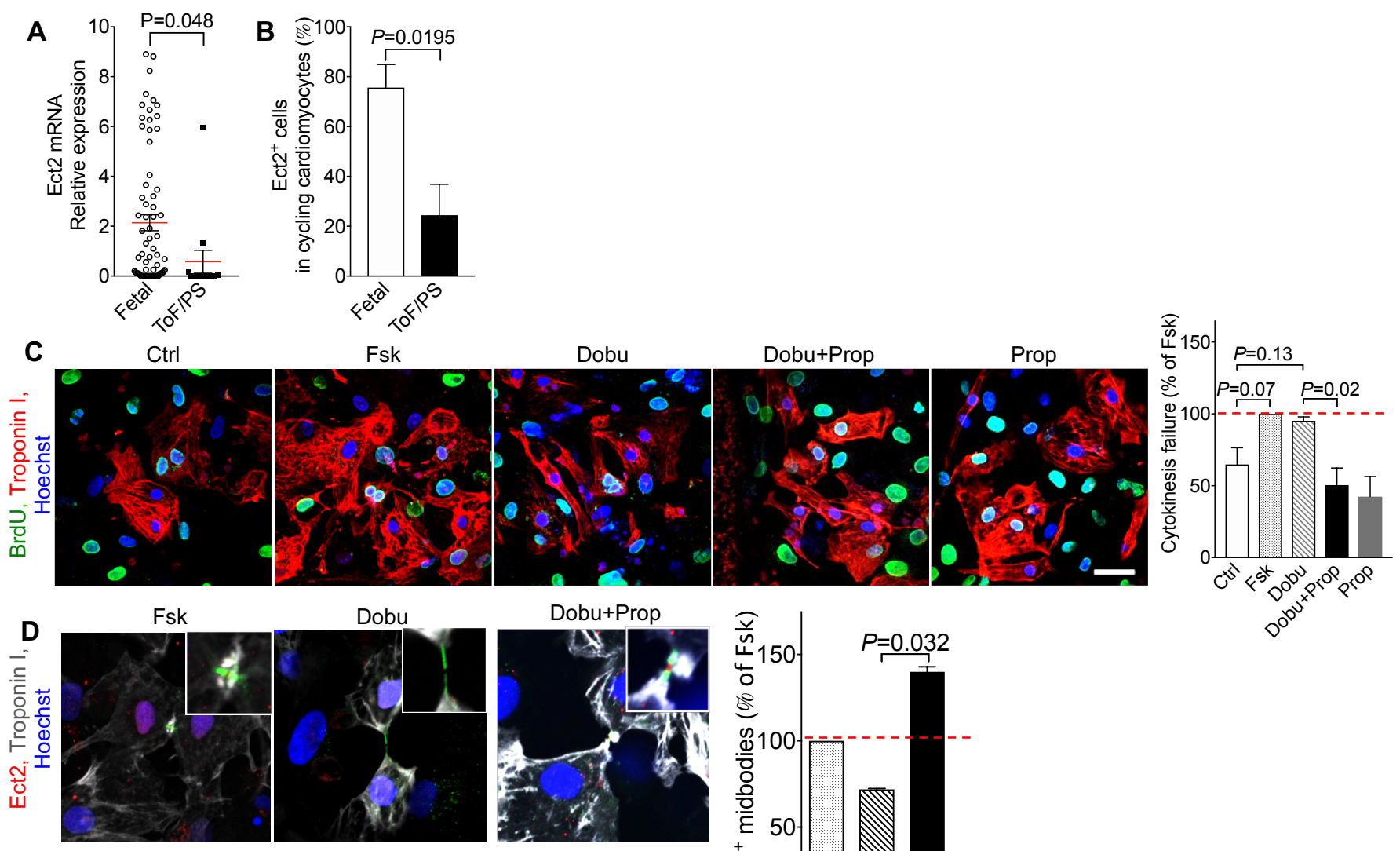

E
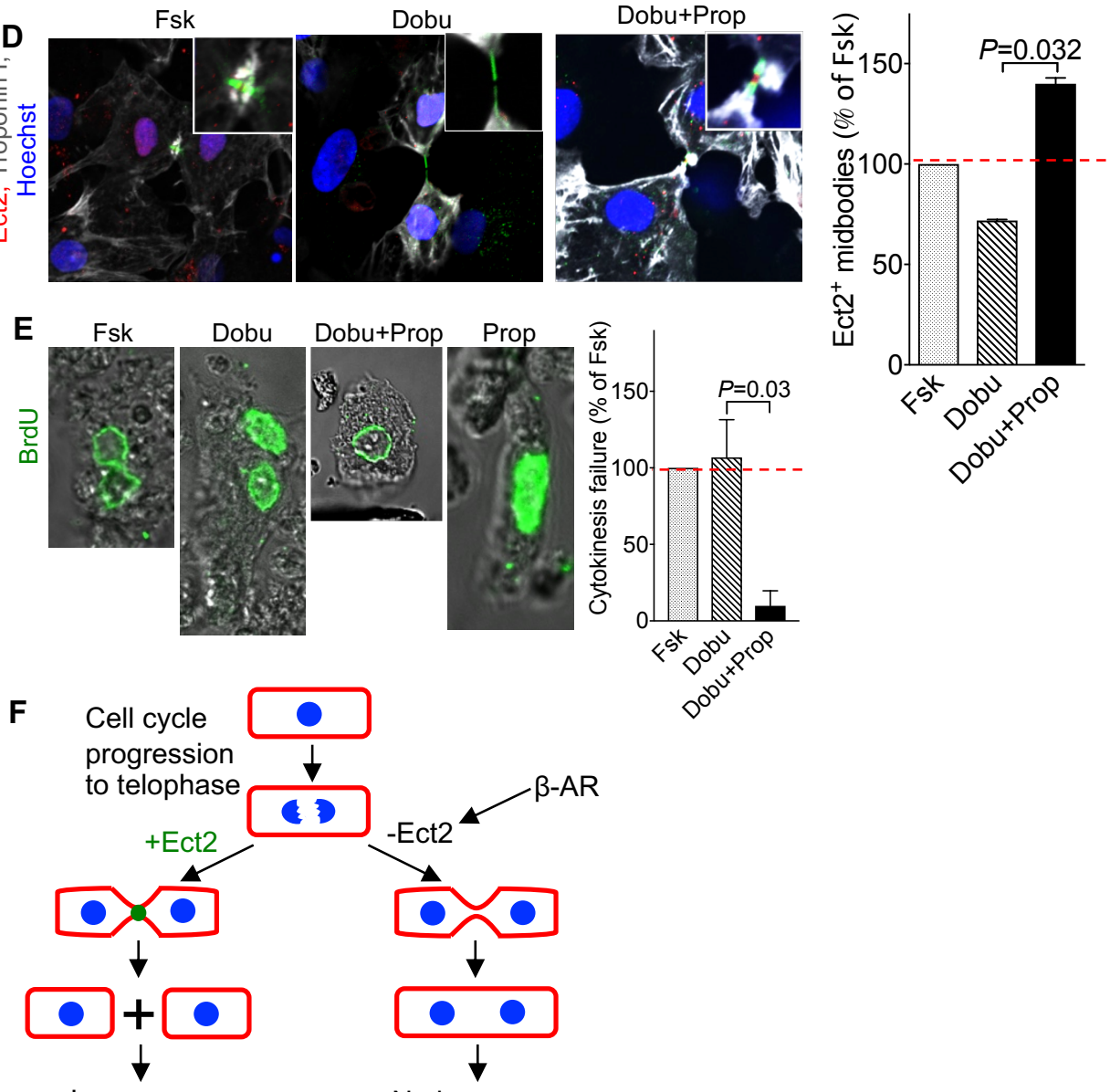

Increase

of endowment

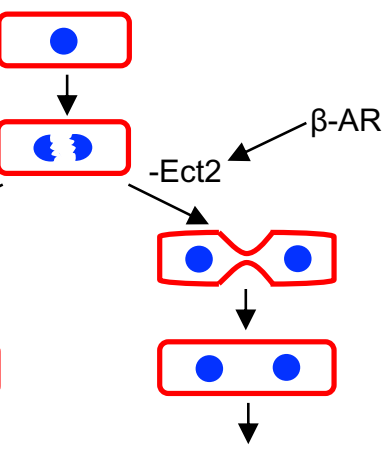

No increase

of endowment

Figure 5. $\boldsymbol{\beta}$-adrenergic signaling regulates cytokinesis in cardiomyocytes from ToF/PS patients. (A) Cardiomyocytes from ToF/PS patients exhibit decreased levels of Ect2 mRNA. Each symbol represents one cycling cardiomyocyte. (B) The percentage of Ect2-positive cycling cardiomyocytes was reduced in ToF/PS patients, compared with fetal human hearts. (A-B, Fetal: $n=71$ cardiomyocytes from 4 hearts, ToF/PS: $n=13$ cardiomyocytes from 3 hearts). (C, D) $\beta$-AR signaling regulates cytokinesis failure in cultured human fetal cardiomyocytes ( $n=$ isolations from 3 hearts; Ctrl: control; Fsk: Forskolin, Prop: Propranolol; Dobu: Dobutamine: $10 \mu \mathrm{M})$, measured by reduced formation of binucleated daughter cells (C) and higher prevalence of Ect2-positive midbodies (D). (E) Propranolol increases completion of cytokinesis in cultured ToF/PS cardiomyocytes ( $n=$ cultures from 3 patients). (F) Model connecting cytokinesis failure to endowment changes. Scale bar: $40 \mu \mathrm{m}(\mathbf{C})$. Statistical significance was tested with T-test (A) and one-way ANOVA with Bonferroni's multiple comparisons test (C-E). 


\section{Supplementary Materials for \\ Control of cytokinesis by $\beta$-adrenergic receptors indicates an approach for regulating cardiomyocyte endowment}

Honghai Liu ${ }^{\dagger}$, Cheng-Hai Zhang ${ }^{\dagger}$, Niyatie Ammanamanchi ${ }^{\dagger}$, Sangita Suresh, Christopher Lewarchik, Krithika Rao, Gerrida M. Uys, Lu Han, Maryline Abrial, Dean Yimlamai, Balakrishnan Ganapathy, Christelle Guillermier, Nathalie Chen, Mugdha Khaladkar, Jennifer Spaethling, James H. Eberwine, Junhyong Kim, Stuart Walsh, Sangita Choudhury, Kathryn Little, Kimberly Francis, Mahesh Sharma, Melita Viegas, Abha Bais, Dennis Kostka, Jun Ding, Ziv Bar-Joseph, Yijen Wu, Matthew L. Steinhauser, Bernhard Kühn*

$\dagger$ Equally contributing authors.

*Corresponding author. Email: Bernhard.kuhn2@,CHP.edu

\section{Supplementary Materials Contents:}

Materials and Methods

Figures S1 - S9

Tables S1 - S8

Captions for Videos S1 - S7

Other Supplementary Materials for this manuscript includes the following:

Table S1 (uploaded separately in an excel file)

Videos S1 - S7 


\section{MATERIALS AND METHODS}

Study design and statistics. The study design, including the number of animals and the numbers of the cells counted, was predefined by the investigators. The genotypes of all pups were recorded throughout the entire period of the project. For the studies involving human tissue, the number of tissue samples was determined according to the availability of the samples. The investigators were blinded for the quantification of samples. The number of biological and technical replicates is provided in Table S4.

Approval of research involving animals and humans. Animal experiments were approved by the Institutional Animal Care and Use Committee (IACUC). Research involving human hearts was approved by the Institutional Review Board (IRB). Myocardium was resected as part of standard care.

\section{Isolation of cardiomyocytes for culture}

The Neomyts Cardiomyocyte isolation kit (Cellutron) was used to isolate cardiomyocytes from the fresh heart tissue (rat, mouse, and human) for cell culture study, according to the protocol provided by the vendor. The isolated rat and mouse cardiomyocytes were cultured on glass surface coated with fibronectin $(10 \mu \mathrm{g} / \mathrm{ml})$. The isolated human fetal/infant cardiomyocytes were cultured on glass surface coated with laminin $(20 \mu \mathrm{g} / \mathrm{ml})$.

\section{Isolation of intact cardiomyocytes for quantification}

We used a previously validated Fixation-Digestion method to isolate intact cardiomyocytes from fresh or frozen myocardium for quantification ${ }^{1}$. The fresh or frozen myocardium was cut into $1 \mathrm{~mm}$ sized tissue blocks followed by incubation with 3.7\% formaldehyde at room temperature 
for 1.8 hours. After being washed with PBS 3 times to remove the formaldehyde, the fixed tissue blocks were digested in enzyme solution (Collagenase B, $3.6 \mathrm{mg} / \mathrm{ml}$; Collagenase D, $4.8 \mathrm{mg} / \mathrm{ml}$ ) at $37^{\circ} \mathrm{C}$, with $10 \mathrm{rpm}$ rotation. The digested cells were collected every 24 hours from the supernatant, and the undigested tissue was re-suspended with fresh enzyme solution until all of the tissue pieces were digested. All of the digested cells from the same heart were then transferred to the same tube and allowed to settle to the bottom of the tube. The cell pellet was collected for further study.

\section{Mouse strains}

Mouse strains expressing fluorescent cardiomyocyte marker and cell cycle reporter. Transgenic mAG-hGem mice were generated by Sakaue-Sawano et al ${ }^{2}$. mAG-hGem consists of a green fluorescent protein, mAG 339 (monomeric Azami Green), fused to ubiquitination domains (110 amino acid residues at the N-340 terminus) of human DNA replication factor, serving as a cell cycle reporter in individual cells. As a result, cells with $\mathrm{S} / \mathrm{G} 2 / \mathrm{M}$ phase nuclei appear green. $\beta$ MHC-YFP knock-in mice were provided by Oliver Smithies ${ }^{3}$. We bred mice expressing both the mAG-hGem and $\beta$ MHC-YFP constructs by crossing mAG-hGem homozygous mice with $\beta$ MHC-YFP homozygous mice.

Inactivation of Ect $2^{f l o x}$ gene in vivo, genotyping, and phenotyping. The Ect2 flox gene was

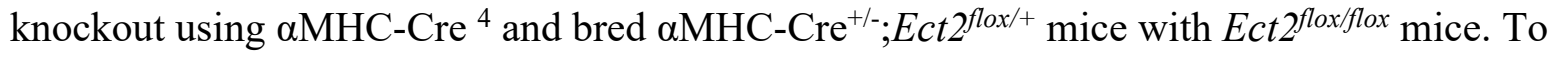
knockout the $E c t 2^{f l o x}$ gene in newborn mice pups, we bred $\alpha \mathrm{MHC}-\mathrm{MerCreMer}{ }^{+/} ; E c t 2^{f l o x /+}$ mice. The newborn pups were administrated tamoxifen ( $30 \mu \mathrm{g} / \mathrm{g}$ body) through i.p. injection once daily from P0 to P2. The inactivation of Ect $2^{\text {flox }}$ gene was confirmed by PCR analysis of genomic DNA, as previously described. ${ }^{5}$ The hearts were isolated, weighed, and imaged with a Leica 
dissection microscope equipped with a Nikon DSFi2 5 MP camera, or isolated for culture as described above.

Administration of propranolol and forskolin to ICR CD-1 mouse. Propranolol (10 $\mu \mathrm{g} / \mathrm{g}$ body weight, 2 injections/day) and forskolin ( $1 \mu \mathrm{g} / \mathrm{g}$ body weight, 1 injection/day) was administered, respectively, to newborn mice from P1 to P8 via intraperitoneal (i.p.) injection. PBS was injected as the control group.

Timed pregnancies. Breeding was set up in the evening. Plugs were checked early the next morning and, if present, this was set as embryonic day 0.5 .

\section{Video microscopy}

To study the cleavage furrow regression in neonatal rat ventricular cardiomyocytes (NRVM), the cardiomyocytes were isolated from neonatal rats (P2) were cultured in NS Medium for 48 hours prior to live cell imaging. The isolated cardiomyocytes were cultured in NS Medium containing $50 \mathrm{ng} / \mu \mathrm{L}$ NRG-1 (R\&D Systems) in fibronectin-coated $35 \mathrm{~mm}$ glass bottom dishes (Part No. P35G-2-14-C-Grid, MatTek Corporation) or 8-well chambered coverglass (Part No. 155409, Lab-TekII). Cardiomyocytes were maintained in an environmental chamber (Tokai-HIT) fitted on the motorized stage (Prior) of an inverted Olympus IX81-ZDC autofocus drift-compensating microscope. Images were acquired at multiple positions every 30 minutes by a CCD camera (Hamamatsu) using an Olympus APON60XOTIRF objective, NA 1.49, together with differential interference contrast (DIC) components. Image acquisition and analysis were done using Slidebook ${ }^{\mathrm{TM}} 5.0$ software. 
To characterize the effect of Ect2 overexpression, neonatal rat cardiomyocytes (P2) were cultured in NS medium containing 10\% FBS (Cellutron Life Technologies) for 3 hours to allow the cells to attach to the surface of an 8-well chambered cover glass coated with fibronectin (20 $\mu \mathrm{g} / \mathrm{ml}$ ). To remove unattached cells, the NS medium was changed carefully to DMEM/F12 (no phenol red) containing 5\% FBS and adenovirus (Adv-Ect2-GFP, MOI = 2,000; Adv-GFP, MOI $=500$ ). The chambered cover glass was mounted to an onstage incubator (Tokai Hit) providing a physiological environment $\left(37^{\circ} \mathrm{C}\right.$, humidity, air mixture containing $\left.5 \% \mathrm{CO}_{2}\right)$ on the motorized stage of a Nikon TiE microscope. Time-lapse imaging was performed for 72 hours. Images were acquired at 10-minute intervals by a CMOS camera (Andor Zyla) using a Nikon Plan Apo 60X oil objective, utilizing the Nikon perfect focus system (PFS) together with filter sets for observing GFP fluorescence. Image acquisition and analysis were done using Nikon NIS Elements 4.5 software.

\section{Single mouse cardiomyocyte transcriptional profiling and data analysis}

The freshly isolated cardiomyocytes from fetal (E14.5) and neonatal (P5) transgenic mAG-hGem mice were sorted on a FACSAria (20 psi, $100 \mu \mathrm{m}$ nozzle, Becton Dickenson Biosciences). The cycling cells $(\mathrm{mAG}+)$ were separated from non-cycling cells (mAG-) based on the fluorescent signals (Fig. S2). The cardiomyocytes were identified by examining the expression of cardiomyocyte specific gene, Tnnt2, and non-cardiomyocyte contamination was identified and excluded by examining the expression of Pdgfrb gene (Fig. S3). Cardiac cells expressing mAGhGeminin transgene (mAG+) were identified using a sequential gating strategy (Fig. S2B-F). Initial size gates for forward scatter (FSC) $v s$. side scatter (SSC) were set to select the large cardiomyocytes corresponding to larger and more granular cells. Cell doublet discrimination was performed by a combination of high forward scatter height and area FSC-H/FSC-A and SSC-H 
vs. SSC-W plots. Live cells were selected by 7-aminoactinomycin D (7AAD, $1 \mu \mathrm{g} / \mathrm{mL}$ final concentration, Invitrogen) live/dead cell distinction staining. Finally, live 7AAD negative cells were distinguished by their mAG fluorescence intensity using the FACSAria 488-nm excitation laser. The $\mathrm{mAG}+$ and $\mathrm{mAG}-$ cell fractions were collected separately for further downstream analyses. FACSDiva Software was used for data acquisition and analysis. The cycling cardiomyocytes (mAG-positive) were sorted into 96-well plates containing reverse transcriptase buffer for the following linear amplification. The freshly isolated single cardiomyocytes from the human myocardium collected during surgery (ToF/PS) and abortion (Fetal) were FAC sorted into 96-well plates containing reverse transcriptase buffer for the following transcriptional profiling and RNA sequencing. Following the synthesis of the first strand of cDNA, the molecular identity of the collected cardiomyocytes was confirmed by PCR for positive expression of the cardiomyocyte-specific gene Tnnt2 and negative expression of the noncardiomyocytes gene Pdgfrb (Fig. S3). After 2 rounds of linear amplification (in vitro transcription), the RNA samples were sequenced using HiSeq 2500 (Illumina). To analyze the data of RNA sequencing, we first trimmed reads for adapters and poly(A) contamination using trimmomatic ${ }^{6}$. We then mapped the trimmed pair-end reads to human/mouse genome build hg19 using HISAT2 (ref. ${ }^{7}$ ).

Using human/mouse gene annotations (.gtf) downloaded from iGenomes, we assigned read counts to genes using HTSeq and htseq-count ${ }^{8}$. Only exonic reads were counted with overlap assigned using the intersection non-empty method. We then further filtered all human samples by removing those with less than $60 \%$ overall reads mapping ratio and less than 1000 expressing genes. The remaining samples were used for further analysis. Finally, to mitigate the difference between samples (e.g. reads counts difference due to variable sequencing depth), we normalized the samples using the housekeeping genes. We started by normalizing the gene expression 
(exonic reads count) to total mapped reads in the sample. Next, we obtained a list of housekeeping genes with most stable expression in heart from the study as reference genes ${ }^{9}$. For each sample, we calculated the geometric mean of those reference genes. Then, we calculated the average of the geometric mean across all samples. This average was further divided by the geometric mean of the reference genes in each sample to get a sample-specific normalization factor. Multiplying the gene expression counts by the lane-specific normalization factor, we get the normalized expression. Lastly, we converted the normalized expression into $\log 2$ space.

\section{Reverse transcription and real-time RT-PCR detection of mRNA levels}

The mRNA was extracted from cardiac tissue samples using TRIzol reagent (Life Technologies) following the protocol provided by the vendor. Briefly, the samples were first homogenized using a mortar and pestle. The TRIzol reagent $(1 \mathrm{~mL})$ was added for each homogenized sample. Homogenized samples in TRIzol reagent were incubated at room temperature for 5 minutes, after which $0.2 \mathrm{~mL}$ of chloroform was added to each $1 \mathrm{~mL}$ of TRIzol. The mixtures were shaken by hand for 15 seconds and then incubated for 2-3 minutes at room temperature. The mixtures were then centrifuged at $12,000 \times \mathrm{g}$ for 15 minutes at $4^{\circ} \mathrm{C}$. The clear upper aqueous phase containing the isolated RNA was carefully removed. The RNA was purified using the Qiagen RNeasy Plus Mini kit per the manufacturer's instructions. The purified RNA was then quantified on a Nanodrop. Reverse transcription was performed on the purified RNA using the BioRad iScript cDNA synthesis kit (Catalog \# 1708890). The kit was used according to the vendor protocol.

\section{TaqMan assay for gene expression analysis}

qRT-PCR was performed using Fast Taqman reagents (Thermo-Fisher). Probes were obtained from Thermo-Scientific including CYR61 (Mm00487498_m1), CTGF (Mm01192933_g1), 
ECT2 (Mm00432964_m1), and 18S (4319413E). All reactions were performed using a 1:10 diluted cDNA while mRNA expression levels were estimated using the 2DDCt method.

\section{Ect2 mRNA expression in cultured NRVMs after forskolin treatment}

The fresh isolated P2 NRVMs were treated with $10 \mu \mathrm{M}$ forskolin for 3 days in culture. The Ect2 mRNA was quantified by qPCR using the method described above. The primers are listed in Table S5.

\section{Adenoviral transduction, quantification of bi/multi-nucleation, and cell cycle activity} To overexpress Ect2 in primary cardiomyocytes, GFP-tagged full-length Ect $2^{10}$ was cloned into pAd/CMV/V5-DEST ${ }^{\mathrm{TM}}$ gateway vector (Thermo Fisher, Cat\#: V49320) and adenoviruses were generated in 293A cells according to the manual's instructions. The isolated cells were cultured for 12 hours, washed gently with culture medium, and then cultured in the culture medium containing adenovirus $(\mathrm{Adv}-\mathrm{Ect} 2-\mathrm{GFP}, \mathrm{MOI}=2000 ; \mathrm{Adv}-\mathrm{GFP}, \mathrm{MOI}=500)$ and $\mathrm{BrdU}(30$ $\mu \mathrm{M})$. After being cultured for 48 hours, the medium was replaced by fresh culture medium containing BrdU $(30 \mu \mathrm{M})$ without adenovirus (48 hours). The cells were then fixed at day 5 and stained for BrdU and pan-cadherin or H3P. The binucleation of BrdU-positive cardiomyocytes and H3P-positive cardiomyocytes was quantified.

\section{Examination of TEAD-binding sites by Luciferase Assay}

Construct preparation: To generate deletions of the Ect2-promoter region, we first subcloned the $2.8 \mathrm{~kb}$ Ect2 promoter region into the luciferase reporter construct pGL4.10 (Promega, Madison WI). Using this construct, we generated a deletion construct that removed all five TEADbinding sites and the DNA between them (Ect2-Promoter $\left.-\Delta_{2 \mathrm{~kb}}\right)$ and a construct that only 
removed the nucleotides of the binding sites (Ect2-Promoter- $\Delta_{1-5}$ ). All plasmid constructs were amplified using TOP-10 competent bacteria and plasmid DNA was isolated and purified using the Qiagen Midi-Prep System (Qiagen, Germany) according to the manufacturer's instructions. Once purified, the plasmid constructs were sequence-verified to eliminate the possibility of unwanted mutations. Transfection into HEK-293 cells: To measure the ability of the Ect2promoter regions to generate a luciferase signal, we transfected HEK-293 cells with the following plasmids: 1) wt-Ect2-promoter-pGL4.10; 2) Ect2-Promoter $-\Delta_{2 \mathrm{~kb}}-$ pGL4.10; 3) Ect2Promoter- $\Delta_{1-5}$-pGL4.10; 4) Empty - pGL4.10; 5) pGL3.1-Renilla-Control. $4 \mu \mathrm{g}$ of plasmid DNA were transfected into one well of a 6-well plate of HEK-293 cells using the lipofectamine 2,000 system (Invitrogen, CA) according to the manufacturer's instructions. Each pGL4.10 group was transfected along with an equal amount of the pGL3.10-Renilla-Control vector. Following transfection, the cells were allowed to incubate in a standard tissue culture incubator for 48 hours to allow for optimal luciferase construct expression. Quantification of Ect2 promoter activity: To perform the luciferase measurements on cells transfected with Ect2promoter deletions, we used the Dual Luciferase Reporter Assay System \#E1910 (Promega, Madison, WI). After 48 hours of incubation, the media was removed and the cells were washed 2 times with PBS. Then the cells were lysed through incubation in the supplied passive lysis buffer for $20 \mathrm{~min}$. After lysis, the mixture was centrifuged at 13,000 x g for 5 minutes to pellet the debris, and the cell lysate was collected for subsequent analysis. The luciferase activity in each group was quantified according to the manufacturer's instructions. We prepared solutions of the Stop-n-Glo reagent and the Luciferase Assay II reagent (LAR2) as described in the manufacturer's instructions. The prepared solution was then loaded into the injectors of a Synergy H1 Hybrid plate reader (Biotek, Winooski, VT), and the first $100 \mu$ of the solution was dispensed. We then placed $20 \mu \mathrm{l}$ of cell lysate into the bottom of a Greiner Cellstar ${ }^{\mathrm{TM}}$ microclear 
bottom 96-well plate (Sigma, St. Louis, MO) and loaded it into plate reader. $100 \mu 1$ of LAR2 was then dispensed into 1 well and measurement of firefly luciferase was taken over a period of $10 \mathrm{sec}$. After measurement, $100 \mu \mathrm{l}$ of Stop-n-Glo reagent was injected into the same well and incubated for $5 \mathrm{sec}$ to quench the firefly luciferase reaction. The measurement of Renilla-control luciferase was performed for 10 seconds to measure the background luminescence activity. The measurement was repeated for each well. The difference between luminescence obtained from the experimental firefly luciferase and the Renilla luciferase measurements was calculated as the activity of the Ect 2 promoter. The cell lysate from each transfection was transferred to 10 wells of a 96-well plate. The values of the activity of the transfected Ect2 promoter were averaged among the 10 wells.

\section{Immunocytology and Immunohistology}

To study the cultured cardiomyocytes attached to the surface of substrate, the cultured cardiomyocytes were fixed with $3.7 \%$ formaldehyde or $4 \%$ paraformaldehyde for 12 minutes at room temperature. After being washed in PBS 3 times, the cells were immersed in permeabilizing and blocking solution ( $0.5 \%$ Triton $\mathrm{X}-100,5 \%$ donkey or goat serum in PBS) for 30 minutes. Then the mixture of primary antibodies was added to the samples and incubated overnight at $4{ }^{\circ} \mathrm{C}$. After being washed 3 times in PBS, the cells were immersed in a mixture of secondary antibodies and incubated for 1 hour at room temperature. The nuclei were counterstained with Hoechst 33342 (Invitrogen, dilution 1:1000) for 5 minutes at room temperature. Then, the samples were dipped into distilled water for 15 seconds. The cells were mounted in $10 \mu 1$ mounting media containing $1 \% \mathrm{~N}$-propyl-gallate dissolved in glycerol and sealed with nail polish.

To study the activity of RhoA (RhoA-GTP) at the midbody, the cells were fixed in $0.5 \mathrm{ml}$ ice-cold trichloroacetic acid (TCA) solution (10\% w/v) for 15 minutes and then washed 3 times with PBS 
containing $30 \mathrm{mM}$ glycine ${ }^{11,12}$. The cells were incubated in an ice-cold mixture of permeabilizing and blocking solution (5\% goat serum, Triton X-100 $0.5 \mu \mathrm{l} / \mathrm{ml}$ in PBS) for 60 minutes. After being washed with PBS containing $30 \mathrm{mM}$ glycine 3 times, the cells were incubated in a mixture of primary antibodies (RhoA-GTP, mouse IgM, New East Biosci, 26904, dilution 1:100); $\alpha$ actinin (mouse IgG1, Sigma A7811, dilution 1:200); Aurora B kinase (rabbit, Abcam, ab2254, dilution 1:200) was added to the samples $\left(50 \mu 1 /\right.$ coverslip) and incubated overnight at $4^{\circ} \mathrm{C}$. After being washed with ice-cold PBS containing $30 \mathrm{mM}$ glycine 3 times, a mixture of secondary antibodies (goat anti-mouse IgG1 633, ThermoFisher A-21126, dilution 1:200; goat anti-mouse IgM 594, ThermoFisher A-21044, dilution 1:200; goat anti-rabbit 488, ThermoFisher A-11034, dilution 1:200) was added to the samples ( $50 \mu 1 /$ coverslip) and incubated for 60 minutes at room temperature. The nuclei were counterstained with Hoechst 33342 (Invitrogen, dilution 1:1,000) for 5 minutes at room temperature. Then the samples were dipped into distilled water for 15 seconds. The cells were mounted in $10 \mu 1$ mounting media containing $1 \%$ NPG dissolved in glycerol and sealed with nail polish.

To stain the Fixation-Digested cardiomyocytes in suspension, if BrdU staining was necessary, the isolated cardiomyocytes were first incubated in $2 \mathrm{~N} \mathrm{HCl}$ solution containing Triton $\mathrm{X}-100$ (Fisher Scientific, BP 151-500) for 60 minutes at room temperature. The $\mathrm{HCl}$ was then neutralized with the same amount of $2 \mathrm{~N} \mathrm{NaOH}$ solution. The isolated cardiomyocytes were then blocked in a solution of 5\% goat serum (Sigma, G9023-10 ML), or donkey serum (Sigma, D9963-10ML), and incubated in primary antibodies at $4^{\circ} \mathrm{C}$ overnight. After PBS wash, the cells were incubated in mixture of secondary antibodies at $4^{\circ} \mathrm{C}$ overnight. The cells were washed with PBS, and incubated in Hoechst solution (PBS, 1:1000) at room temperature for 5 minutes followed by three rounds of PBS wash. The cells were then ready for future study. 
To study the hearts using immunohistology, the hearts were resected and fixed immediately in $3.7 \%$ formaldehyde at room temperature for 8 hours. The fixed hearts were washed in PBS and immersed in $30 \%$ sucrose solution at $4{ }^{\circ} \mathrm{C}$ for 24 hours. After being embedded in optimum cutting temperature (OCT) compound, the frozen block was trimmed and the exposed heart tissue was cut into $20 \mu \mathrm{m}$ thick sections with a Leica CM1950 cryostat and adhered to glass slides (Color Frost, Fisher). The slides were fixed in 3.7\% formaldehyde, permeabilized in $0.5 \%$ Triton X-100, and blocked in PBS containing 20\% goat serum and $0.2 \%$ Tween 20 . Then the mixture of primary antibodies was added to the samples and incubated overnight at $4^{\circ} \mathrm{C}$. After being washed 3 times in PBS, the cells were immersed in a mixture of secondary antibodies, and incubated for 1 hour at room temperature. The nuclei were counterstained with Hoechst 33342 (Invitrogen, dilution 1:1000) for 5 minutes at room temperature. Then, the samples were dipped into distilled water for 15 seconds. The cells were mounted in $10 \mu 1$ mounting media containing 1\% N-propyl-gallate dissolved in glycerol and sealed with nail polish.

\section{Quantification of mouse and rat cardiomyocyte cell cycle activity and proliferation}

To quantify the midbodies of the neonatal rat ventricle cardiomyocytes (NRVMS), we cultured the NRVM (E14.5 and P2) in NS medium for 3 days, then studied the midbodies using immunocytology. We first identified the cleavage furrows of the cycling cells at late cytokinesis stages, i.e. telophase, by visualizing the immunostaining for Aurora B kinase. We then identified cardiomyocytes using the markers troponin I and $\alpha$-actinin, and examined the presence of the Ect2, Racgap 1, or RhoA-GTP at the midbodies.

To count the total number of cardiomyocytes in a mouse heart, all the digested cardiomyocytes from the same heart were suspended in $2 \mathrm{ml}$ PBS buffer. The concentration of the cardiomyocytes inside the PBS buffer was measured using a hemocytometer. The total number 
of cardiomyocytes was then calculated by multiplying the measured cell concentration by the volume of the cell solution $(2 \mathrm{ml})$.

To quantify the binucleation and $\mathrm{H} 3 \mathrm{P}+$ cardiomyocytes in mouse hearts, cardiomyocytes were isolated by fixation-digestion prior to immunostaining. The solution containing the stained cells was then transferred to 8 -well chambered cover glass (400 $\mu 1 /$ well). After the cells were settled down to the bottom of the chambers, the number of mono/bi/multinucleated cardiomyocytes were counted with a fluorescence microscope, and the percentage of mono/bi/multinucleated cardiomyocytes was calculated. To quantify the proportion of H3P-postive cardiomyocytes, the concentration of stained cardiomyocytes in suspension $\left(C_{\text {cardiomyocytes }}\right)$ was first measured using a hemocytometer. The cell suspension $(400 \mu \mathrm{l})$ was then transferred to a well of a chamber slide, and the total number of H3P-positive cardiomyocytes $\left(\mathrm{H}_{\mathrm{H} 3 \mathrm{P}+}\right)$ inside the well was counted with a TiE epifluorescence microscope. The proportion of the H3P-positive cardiomyocytes $\left(\mathrm{P}_{H 3 P+}\right)$ was calculated using the following formula: $\mathrm{H}_{H 3 P+}=\frac{\mathrm{N}_{H 3 P+}}{400 \mu l \times C_{\text {cardiomyocytes }}} \times 100 \%$. To measure the size (2D) of cardiomyocytes in mouse hearts, the cells were imaged using a Nikon TiE microscope with a Zyla CMOS camera. The image layers from the immunofluorescence channels were used to identify cardiomyocytes and the layer from the bright-field channel was used to measure the area of single cardiomyocytes using ImageJ software.

To quantify the bi-and multinucleated cardiomyocytes in mouse hearts, the hearts from the aMHC-Cre;Ect2flox mouse (P1) and the ICR mouse (P4 and P8) were treated with propranolol, forskolin, and PBS were resected and the cardiomyocytes were dissociated using FixationDigestion method and immunostained. The mono/bi/multi-nucleated cardiomyocytes were then quantified under Nikon TiE microscope. About 500 cardiomyocytes in each sample were quantified. 


\section{Mouse left anterior descending (LAD) coronary artery ligation as a model of myocardial}

infarction. Newborn ICR mice were first treated with propranolol (10 $\mu \mathrm{g} / \mathrm{g}, 2$ i.p. injections/day) and PBS, respectively, from P1 to P12. To induce myocardial infarction at 8 to 12 weeks, we permanently ligated the left anterior descending (LAD) artery. Briefly, the mice were anesthetized with $4 \%$ isoflurane and then intubated and ventilated with a stroke volume of $225 \mu 1$ at 145 breaths/minute. The hearts were exposed by performing thoracotomy and the LAD artery was tied with 8-0 nylon suture. After the chest was closed with 6-0 suture, bupivacaine $(8 \mu \mathrm{g} / \mathrm{g})$ was locally administered through subcutaneous injection. The mice were kept intubated without isoflurane for another 30 minutes at room temperature and then at $37^{\circ} \mathrm{C}$ until waking up from the anesthesia. The bupivacaine $(8 \mu \mathrm{g} / \mathrm{g})$ was kept administered through subcutaneous injection in the following 3 days (1 dpi to 3 dpi).

\section{Stereology}

The LAD ligated mouse hearts were isolated, gently washed in PBS, weighed, immersed in cardioplegia solution, and fixed overnight with 3.7\% formaldehyde at room temperature. The hearts were then placed in $30 \%$ sucrose for 48 hours at $4^{\circ} \mathrm{C}$. The atria for each heart were cut off and the ventricles were embedded in OCT.

The hearts were sectioned on Leica CM1950 cryostat in cross-sectional orientation (thickness 15 $\mu \mathrm{m})$, resulting in 75-80 slides/heart with 4 sections each. For random systematic sampling we used a random number generator ranging between 1-6 to determine the first slide and then selected every $17^{\text {th }}$ slide for staining. The tissue sections were stained with $\alpha$-actinin (sarcomeric stain) and Hoechst (nucleus stain). 
The adjacent slides of immunofluorescence-stained slides were selected for AFOG staining and followed the standard lab protocol method. Photomicrographs were taken on Nikon TiE microscope (objective lens 10x).

Quantification of myocardial volume by point count method on AFOG-stained sections: Tissue sections were imaged on Leica MZ26 dissector microscope, zoom factor: 1.0X. The area of myocardium (red after AFOG staining) and scar (blue after AFOG staining) was quantified using ImageJ $1.51 \mathrm{~s}$ version. To this end, the image was overlaid with a grid to determine area per point. The distance between selected sections was calculated ( ${ }^{\text {th }}$ slide $\times$ \# of sections $/$ slide $\times$ section thickness). The LV volume was measured by counting the number of grids on both LV myocardium and the scar region. The scar size was also measured using the same method. Optical dissector method to determine the volume density of cardiomyocyte nuclei: The immunofluorescence stained sections were imaged using Nikon A1R confocal microscope. We selected four random spots on the technically-best section from each slide and analyzed 20 random samples from each heart. The total number of positive cardiomyocyte nuclei per heart was counted and the mean per sample volume was calculated.

Total number of cardiomyocytes (endowment):

Number of cardiomyocytes $=$ Number of cardiomyocyte nuclei $/($ Mono $\%+2 \times B i \%=3 \times$ Tri $\%+$ $4 \times$ Tetra\%)

\section{In vivo Cardiac MRI}

Anesthesia. Mice were anesthetized with $4 \%$ isoflurane mixed with room air in an induction box for 1 to 3 minutes. The depth of anesthesia was monitored by tow reflex, extension of limbs, and spine positioning. Once the plane of anesthesia was established, the mouse was placed on a manually built neonatal mouse holder and the anesthesia was maintained by 1.5 to $2 \%$ isoflurane 
with $100 \%$ oxygen via a nose cone. The respiration was continuously monitored by placing a small pneumatic pillow under the animal's diaphragm which was connected to a magnetcomparable pressure transducer feeding to a physiological monitoring computer equipped with respiration-waveform measuring software (SA Instruments, Stony Brook, NY). The respiration waveform was automatically processed to detect inspiration, expiration and respiration rate.

In vivo CMR Acquisition. In-vivo cardiac MRI (CMR) was carried out on a Bruker Biospec 7T/30 system (Bruker Biospin MRI, Billerica, MA) with the 35-mm quadrature coil for both transmission and reception. Free-breathing- no-gating cine MRI with retrospective navigators was acquired with the Bruker Intragate module.

Late-gadolinium enhancement (LGE) for myocardial infarct evaluation. Subcutaneous injection of Multi Hance (Gadobenate dimeglumine, 529 mg/ml, Bracco Diagnostics, Inc, Monroe Twp, NJ 08831) was administered right before the CMR acquisition with the dosage of in $0.1 \mathrm{mmol}$ $\mathrm{Gd} / \mathrm{kg}$ bodyweight. $\mathrm{T}_{1}$-weighted images to highlight $\mathrm{LGE}$ was acquired $15-20$ minutes after the subcutaneous administration of Multi Hance. Eight $\mathrm{T}_{1}$-weighted short-axis imaging planes covering the whole ventricular volume with no gaps were acquired with the following parameters: Field of view $(\mathrm{FOV})=2.5 \mathrm{~cm} \times 2.5 \mathrm{~cm}$, slice thickness $=1 \mathrm{~mm}$, in-plane resolution $=$ $0.97 \mu \mathrm{m}$, flip angle $(\mathrm{FA})=10$ degrees, echo time $(\mathrm{TE})=3.059 \mathrm{msec}$, repetition time $(\mathrm{TR})=$ $5.653 \mathrm{msec}$.

Cine CMR to determine cardiac function. White-blood cine movies with 20 cardiac phases were acquired for each mouse with equivalent temporal resolution for the cine loops was about 16.5$21.5 \mathrm{~ms}$ per frame. Eight short-axis imaging planes covering the whole ventricular volume with 
no gaps and one long-axis plane were acquired with the following parameters: Field of view $(\mathrm{FOV})=2.5 \mathrm{~cm} \times 2.5 \mathrm{~cm}$, slice thickness $=1 \mathrm{~mm}$, in-plane resolution $=0.97 \mu \mathrm{m}$, flip angle $(\mathrm{FA})$ $=30$ degrees, echo time $(\mathrm{TE})=1.872 \mathrm{msec}$, repetition time $(\mathrm{TR})=38.293 \mathrm{msec}$.

\section{Analysis of CMR results}

Extent of myocardial infarction (MI) by late-gadolinium enhancement (LGE). The extent of myocardial infarction was defined by the percentage of the myocardium displaying hyperintensity 15-20 minutes after Gd administration. To obtain the proportion of myocardial infarction $(M I)$, we measured the angle of the portion of the myocardium displaying hyperintensity in the left ventricle wall of each scanned slice $(i)$ and divided the angle by $360^{\circ}$ to get the percentage of infarction of the slice $\left(M I_{i}\right)$. The infarction of each scanned slice was then averaged to have the proportion of myocardial infarction $M I=\sum_{i} M I_{i}$.

Cardiac function from cine CMR. The left ventricular endocardium and epicardium boundaries of each imaging slice at the end-systole (ES) and the diastole (ED) were manually traced by a blinded operator on the Paravision 5.1 Xtip software (Bruker Biospin MRI, Billerica, MA) to calculate the following functional parameters: left ventricular blood volume (LVV), left ventricular wall volume (LV wall), LV mass, stroke volume (SV), ejection fraction (EF), heart rate (HR), cardiac output (CO), longitudinal shortening, and radial shortening. LVV is calculated by summation of all the short-axis slices. The ejection fraction $(E F)$ was calculated using the following equation: $E F=\frac{\sum_{i} A_{i}^{e d} h_{i}-\sum_{i} A_{i}^{e s} h_{i}}{\sum_{i} A_{i}^{e d} h_{i}} \times 100 \%$, where $A_{i}^{e s}$ is the internal left ventricle area of slice $i$ at end systole, $A_{i}^{e d}$ the internal left ventricle area of slice $i$ at end diastole, and $h_{i}$ is the thickness of each scanned slice. The proportion of left ventricle wall thinning 
caused by adverse remodeling was calculated by measuring the proportion of the angle of the thinned left ventricle caused by adverse remodeling after LAD ligation. To calculate the left ventricle wall thickening, we first selected the scanned slice that demonstrated the largest LGE portion. The thickness at both ends and the middle of the LGE portion was measured at end systole $\left(d^{e s}\right)$ and diastole $\left(d^{e d}\right)$ and calculated the average. The left ventricle wall thickening was calculated through equation $L V$ wall thickening $=\left(d^{e s}-d^{e d}\right) / d^{e d} \times 100 \%$.

\section{Examination of heart function of newborn mice by echocardiography}

We performed echocardiography using a Vevo 770 device (VisualSonics) with a $25 \mathrm{MHz}$ probe (RMV-710B). Two-dimensional (2D) B-mode recordings covering both ventricles were obtained in the left parasternal short axis view. The left ventricular endocardium and epicardium boundaries of the imaging slice at end-systole and diastole were manually traced by a blinded operator on the ImageJ software. The ejection fraction $(E F)$ was calculated using the following

equation: $E F=\frac{A^{e d}-A^{e s}}{A^{e d}} \times 100 \%$, where $A^{e s}$ is the left ventricular blood area at end systole, $A^{e d}$ is the left ventricular blood area at end diastole.

\section{Quantification of cytokinesis in human cardiomyocytes}

To quantify the bi-and multinucleation of intact human cardiomyocytes, the cardiomyocytes in the fresh or frozen right ventricle myocardium collected as part of standard care during surgical repair of the ToF/PS hearts were isolated through Fixation-digestion method, followed by immunostaining as described above. The cells were then imaged and quantified using Nikon A1R microscope for mono/bi/multi-nucleation. The cardiomyocytes isolated from the myocardium without heart disease were used as the control group. 
To quantify the response of human fetal cardiomyocytes to $\beta$-adrenergic receptor signaling reagents, the human fetal cardiomyocytes were isolated from fresh specimen using the Cellutron Kit. The cells were cultured in IMDM media containing 10\% FBS and recombinant neuregulin 1 (rNRG1, $100 \mathrm{ng} / \mathrm{ml}$ ) for 2 days. The cells were then treated with forskolin $(10 \mu \mathrm{M})$, propranolol $(10 \mu \mathrm{M})$, dobutamine $(10 \mu \mathrm{M})$, or a combination of propranolol $(10 \mu \mathrm{M})$ and dobutamine (10 $\mu \mathrm{M})$ for 3 days, in the presence of $\mathrm{BrdU}(30 \mu \mathrm{M})$. The cells were then fixed with 3.7\% formaldehyde and stained using primary antibodies against troponin I (goat, Abcam), pancadherin (rabbit, Abcam) and BrdU (rat, Abcam), and secondary antibodies from donkey against goat, rabbit, and rat IgG, respectively. The proportion of binucleated cardiomyocytes among the BrdU-positive cardiomyocytes was quantified with a Nikon A1R microscope.

To quantify the response of ToF/PS myocardium to $\beta$-adrenergic receptor signaling reagents, the myocardium samples were collected during ToF/PS correction and were cut into $\sim 1 \mathrm{~mm}$ tissue blocks and cultured in IMDM media containing 10\% FBS, recombinant neuregulin 1 (rNRG1, $100 \mathrm{ng} / \mathrm{ml})$, and $\mathrm{BrdU}(30 \mu \mathrm{M})$, for 6 days. During culture, the samples were treated with forskolin $(10 \mu \mathrm{M})$, propranolol $(10 \mu \mathrm{M})$, dobutamine $(10 \mu \mathrm{M})$, or a combination of propranolol $(10 \mu \mathrm{M})$ and dobutamine $(10 \mu \mathrm{M})$. Cardiomyocytes were isolated with the Fixation-Digestion method. After denaturing the DNA with $2 \mathrm{~N} \mathrm{HCl}$, and neutralization with $2 \mathrm{~N} \mathrm{NaOH}$, immunofluorescence antibody labeling was performed in solution. The proportion of binucleated and BrdU-positive was quantified with a Nikon A1R microscope.

\section{Quantification of cardiomyocyte binucleation in ToF/PS patients by Multi-isotope Imaging Mass Spectrometry (MIMS)}

The clinical study protocol was approved by the IRB, and informed consent was obtained from the parents. Based on prior human MIMS studies ${ }^{13,14}$, the patient received ${ }^{15} \mathrm{~N}$-thymidine (50 
$\mathrm{mg} / \mathrm{kg}$ p.o., Cambridge Isotope Laboratories, on five consecutive days) at 3.5 weeks of age. The patient underwent surgery at 6 months of age. A discarded piece of right ventricular myocardium was obtained, fixed in $4 \%$ paraformaldehyde, embedded in LR White, and $500 \mathrm{~nm}$ sections were mounted on silicon chips. Multiple isotope imaging mass spectrometry (MIMS) was performed on myocardial sections utilizing the NanoSIMS 50L (CAMECA) and previously described analytical methods ${ }^{15}{ }^{15} \mathrm{~N}$-thymidine labeling was measured by quantification of the ${ }^{12} \mathrm{C}^{15} \mathrm{~N}^{-}$ ${ }^{12} \mathrm{C}^{14} \mathrm{~N}^{-}$ratio (Fig. S8), obtained in parallel with mass images utilized for histological identification $\left({ }^{12} \mathrm{C}^{14} \mathrm{~N}^{-},{ }^{31} \mathrm{P}^{-},{ }^{32} \mathrm{~S}-\right)$. Quantitative mass images were then analyzed using OpenMIMS version 3.0, a customized plugin to ImageJ (NIH) that is available at https://github.com/BWHCNI/OpenMIMS ${ }^{16}$. An observer blind to the ratio images identified nuclei and assigned cellular identity using the ${ }^{14} \mathrm{~N}\left({ }^{12} \mathrm{C}^{14} \mathrm{~N}-\right),{ }^{31} \mathrm{P}$-, and ${ }^{32} \mathrm{~S}$ - images as previously described ${ }^{15}$. Cardiomyocyte nuclei were identified by their close association with sarcomeric structures.

\section{Statistical analyses}

Statistical testing was performed with Student's t-test, Fisher's exact test, and ANOVA, followed by Bonferroni post hoc testing, as indicated. A two-sided P value $\leq 0.05$ was accepted as statistically significant. Statistical analyses were performed with GraphPad Prism, version 6. 


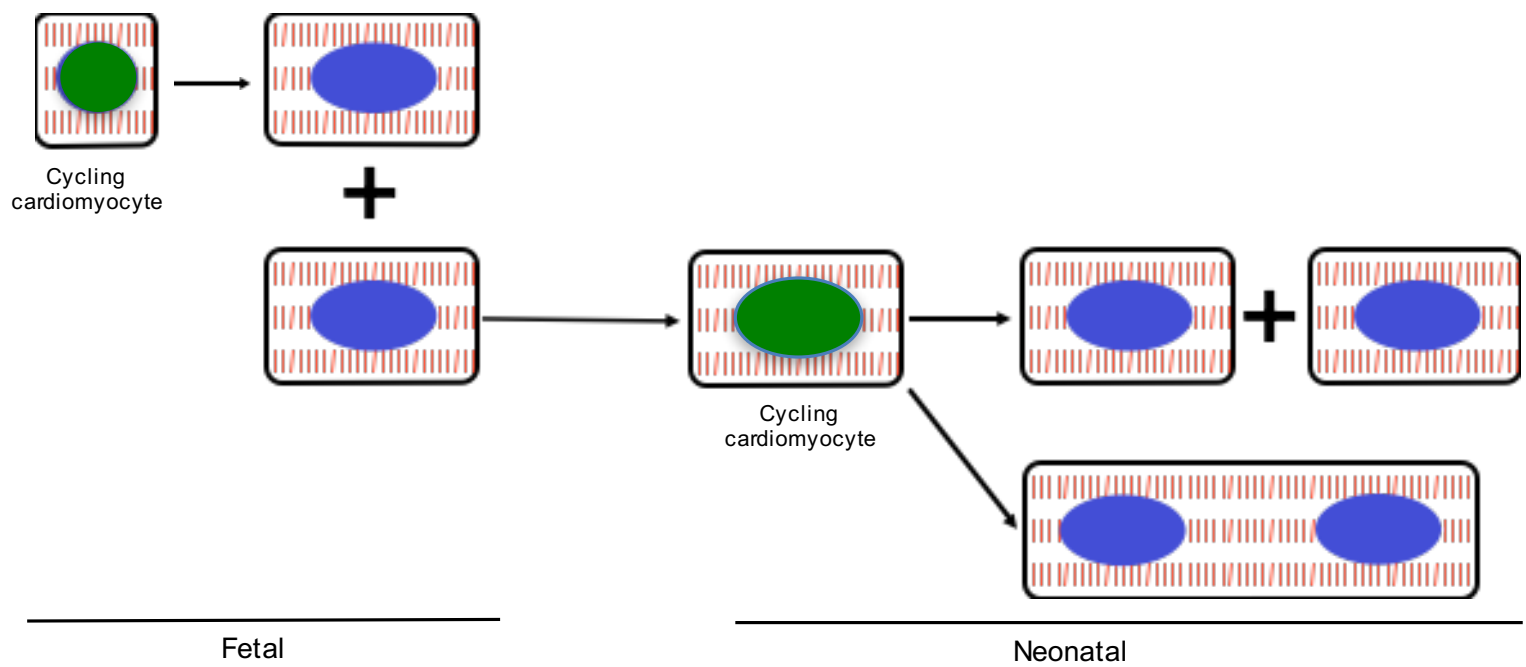

Figure S1. A single-cell transcriptional profiling strategy identifies molecular mechanisms of cardiomyocyte binucleation. When neonatal mouse cardiomyocytes are in the cell cycle, two outcomes are possible: the cardiomyocyte may either divide or become binucleated. As such, bulk RNAseq of cycling neonatal mouse cardiomyocytes would not reveal the molecular mechanisms that are specific for binucleation. To overcome this challenge, we have taken a single cell transcriptional profiling approach, which should isolate the specific molecular mechanism. We identified cycling cardiomyocytes with the Azami green-Geminin (mAG-hGem) reporter and isolated single cycling and not cycling cardiomyocytes with FACS, as demonstrated in Figure S2. 

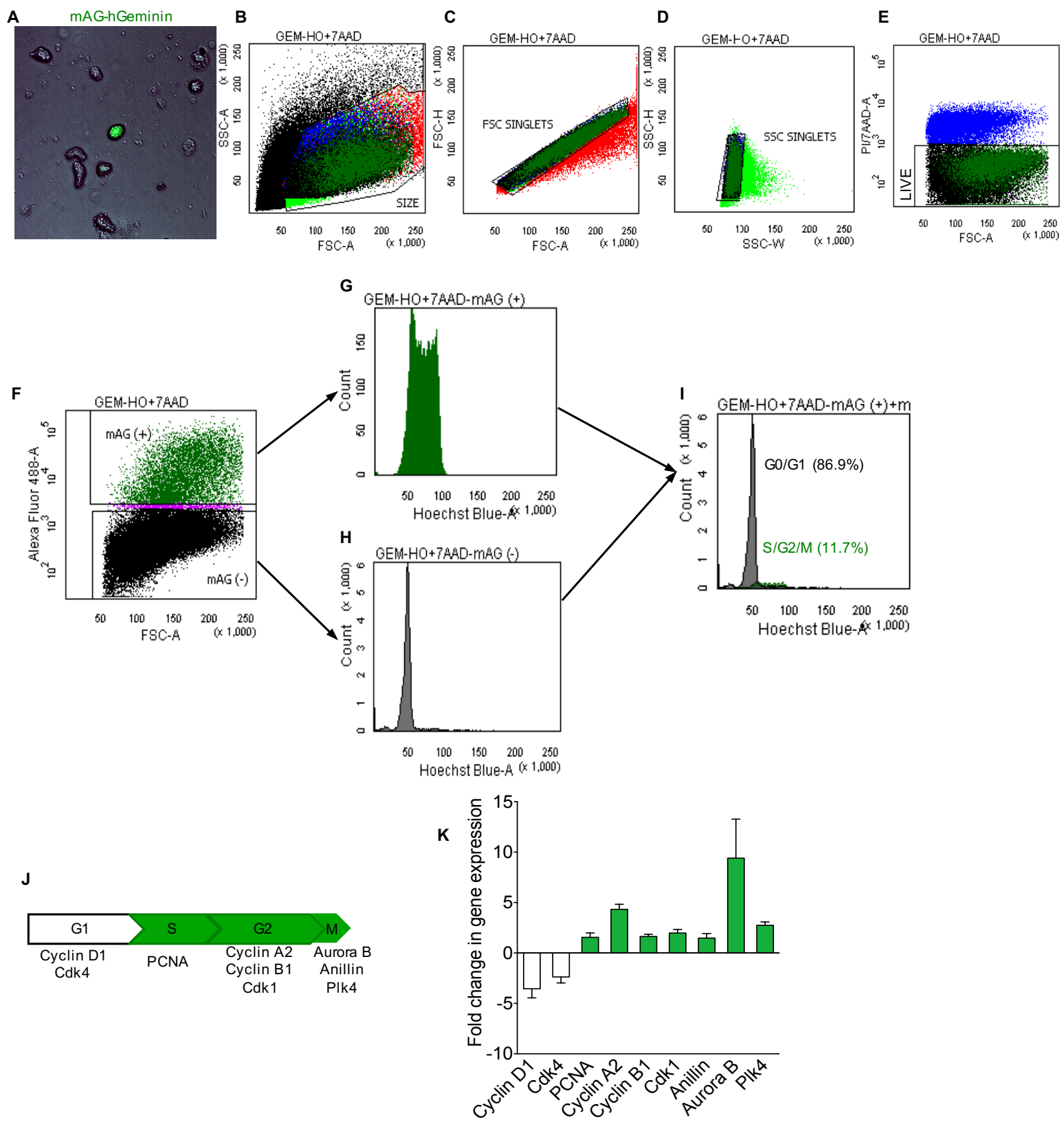

Figure S2. Strategy for isolation and characterization of cycling cardiac cells. (A) Cells were isolated from mAGhGeminin E14.5 hearts and subjected to FACS. Panels (B-F) show FACS gating strategy for isolation of single cycling and non-cycling cardiac cells. We validated that the population of Geminin-positive cells were in the cycle by (G-I) analyzing DNA contents after staining with Hoechst, and (J, K) RT-PCR with primers for cell cycle genes. Cells were gated sequentially for size $(\mathbf{B})$, doublet exclusion $(\mathbf{C}, \mathbf{D})$, viability $(\mathbf{E})$, and $\mathrm{mAG}-\mathrm{hGeminin}$ expression $(\mathbf{F})$.

Representative histograms of cycling Geminin-positive cells $(\mathbf{G})$, non-cycling Geminin-negative cells $(\mathbf{H})$, and merge of cycling Geminin-positive cells and non-cycling Geminin-negative cells show that Geminin-positive cells have higher DNA content (I). (J) Linear cell cycle diagram with marker genes selected for identification of cell cycle phases indicated below. The phases of the cell cycle indicated by mAG-hGeminin (S-, G2- and M-phase) are highlighted in green. (K) RT-PCR analysis of Geminin-positive cells shows no expression of the G1 phase markers cyclin D1 and Cdk4. Genes indicating S-, G2-, and M-phase are expressed and corresponding columns are indicated in green. All PCR data were normalized to the expression of the housekeeping genes GAPDH and ACTB. Mean $\pm \mathrm{SD}$ of three technical replicates are shown. 

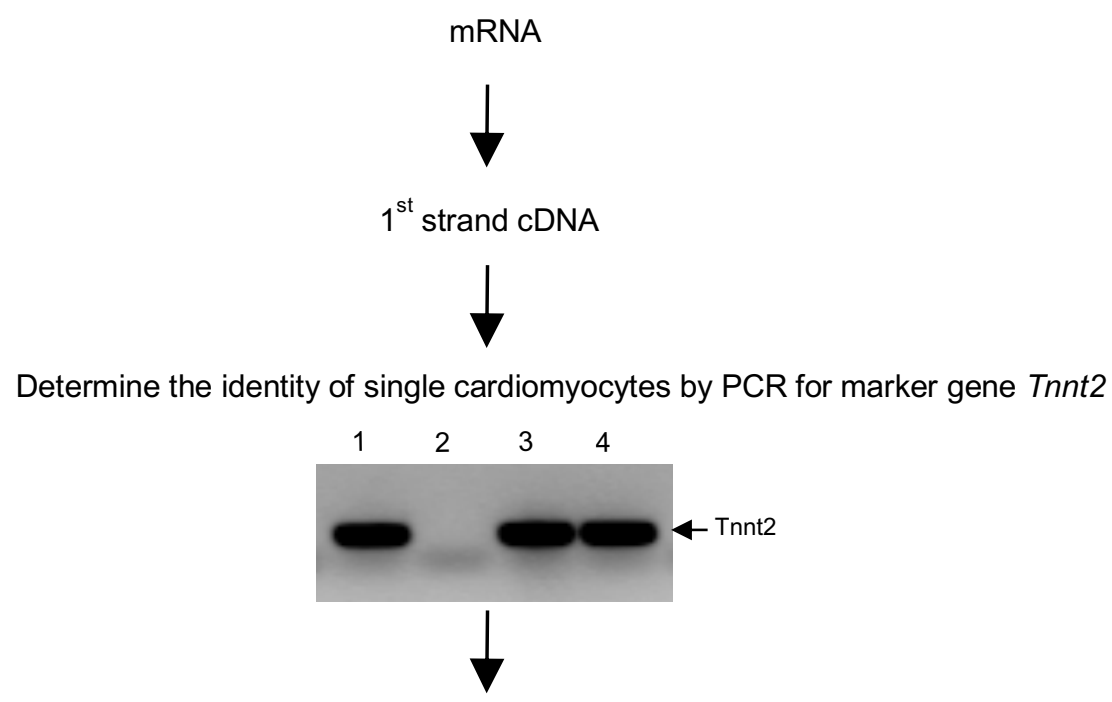

Determine contamination with non-cardiomyocytes by PCR of Pdgfrb

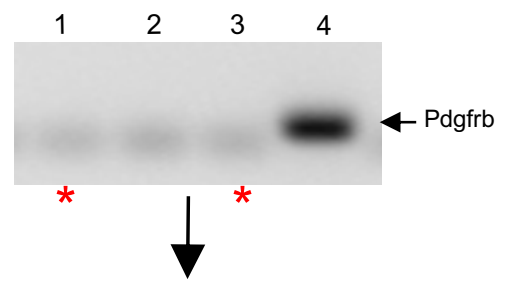

Select Tnnt2 positive and Pdgfrb negative cardiomyocytes for amplification

Figure S3. Strategy for identifying single cardiomyocytes. Ventricular cardiac cells were dissociated by enzymatic digestion from Azami green geminin (mAG-Geminin) transgenic mice and sorted by FACS (as explained in Figure S2). Following cell lysis, mRNA was reverse transcribed into 1st strand cDNA. Single cell cDNA was subjected to PCR using the cardiomyocyte-specific marker, troponin T2 (Tnnt2). Potential contamination with non-cardiomyocytes (i.e. cardiac fibroblasts and endothelial cells) was detected by PCR for platelet derived growth factor receptor $\beta$ (Pdgfrb). Gel electrophoresis of single cells are shown. Single cells showing Tnnt2 positive and Pdgfrb negative were considered as confirmed cardiomyocytes, i.e. cells $1 \& 3$ (indicated by red asterisks). Cells expressing both genes or neither gene were eliminated. Taken together, our isolation and identification method yielded $40-60 \%$ of single cardiomyocytes for single-cell linear amplification and sequencing. 


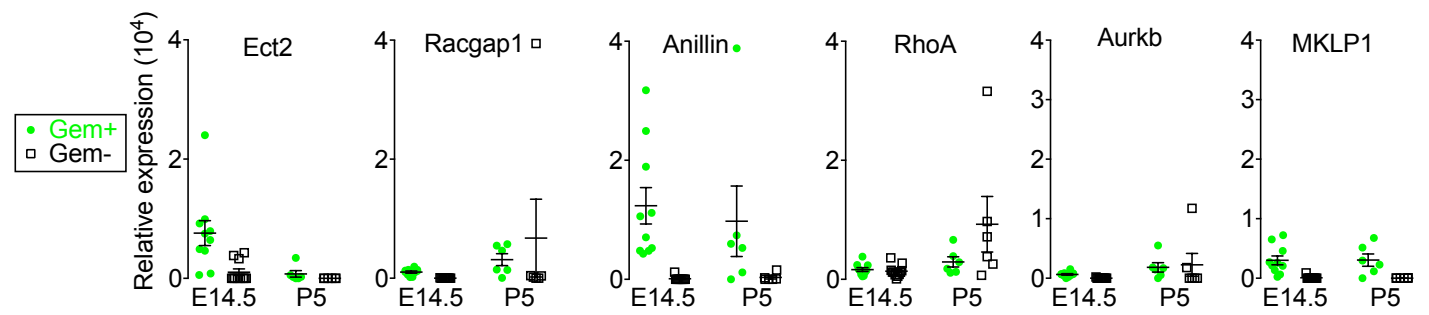

Fig. S4 Expression levels of selected cytokinesis genes are graphed for single cardiomyocytes at E14.5 and P5. Mean \pm SEM are indicated. 

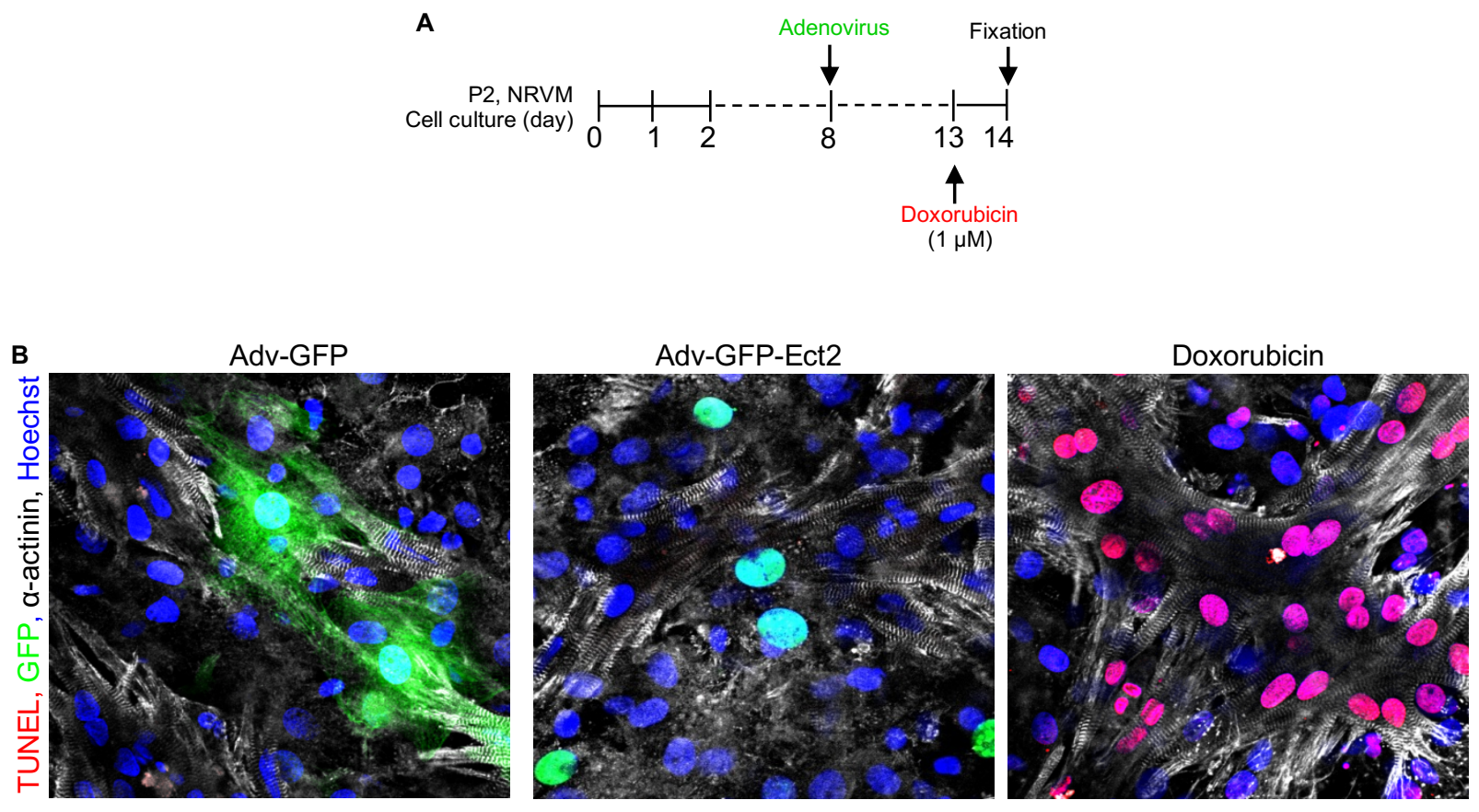

Figure S5. Adenoviral-mediated transduction of Ect 2 does not induce apoptosis in cultured neonatal rat ventricular cardiomyocytes (NRVMs). The fresh isolated NRVMs were first cultured for eight days, then Ect2 was expressed in the cells through adenoviral-mediated transduction (Adv-GFP-Ect2, MOI $=200$ ). The transduction of GFP (MOI $=50)$ was used as negative control. As a positive control, the NRVMs were treated with doxorubicin (1 $\mu \mathrm{M})$ to induce apoptosis in the cells. (A) Design of the apoptosis assay. (B) Apoptosis was detected with the ApopTag Red In Situ apoptosis detection kit (EMD Millipore corporation), using Doxorubicin as a positive control. 


\section{A}
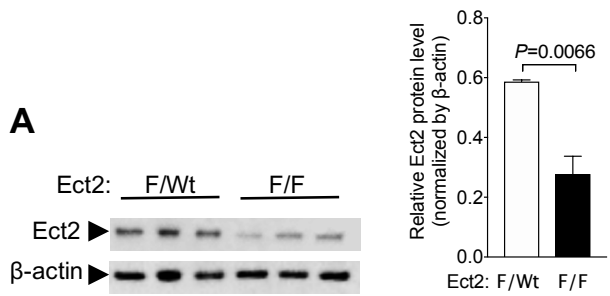

B

\begin{tabular}{|c|c|c|c|c|c|c|c|c|c|}
\hline \multicolumn{2}{|c|}{ Time Points in the Study } & \multirow{2}{*}{$\begin{array}{l}\text { Total number of } \\
\text { the animals }\end{array}$} & & \multicolumn{3}{|c|}{ Cre- } & \multicolumn{3}{|c|}{$\mathrm{Cre}^{+}$} \\
\hline Ect2 inactivation & Analysis of pups & & & Ect2 $\mathrm{FMm}$ & Ect2 ${ }^{F / F}$ & P-value & Ect2 ${ }^{F / M t}$ & Ect $2^{\mathrm{F} / \mathrm{F}}$ & $P$-value \\
\hline \multirow{6}{*}{$\begin{array}{c}\text { E9.5 } \\
\text { (aMHC-Cre) }\end{array}$} & \multirow{2}{*}{$\begin{array}{c}\text { P0 } \\
\text { (Natural birth) }\end{array}$} & \multirow{2}{*}{64} & Expected & 16 & 16 & \multirow{2}{*}{0.62} & 16 & 16 & \multirow{2}{*}{0.036} \\
\hline & & & Observed & 19 & 13 & & 25 & 7 & \\
\hline & \multirow{2}{*}{ P1 } & \multirow{2}{*}{61} & Expected & 16 & 16 & \multirow{2}{*}{0.62} & 16 & 16 & \multirow{2}{*}{0.014} \\
\hline & & & Observed & 19 & 13 & & 24 & 5 & \\
\hline & \multirow{2}{*}{ P2 } & \multirow{2}{*}{56} & Expected & 16 & 16 & \multirow{2}{*}{0.62} & 16 & 16 & \multirow{2}{*}{$<0.0001$} \\
\hline & & & Observed & 19 & 13 & & 24 & 0 & \\
\hline
\end{tabular}

Figure S6. Survival analysis shows that Ect2 gene inactivation in development induces decreased pup

viability. To decrease the cardiomyocyte endowment, we inactivated Ect ${ }^{\text {Flox }}$ with $\alpha$ MHC-Cre in embryonic mouse hearts. (A) Western blot shows 35\% protein reduction in $\alpha \mathrm{MHC}-\mathrm{Cre}$; Ect2F/F mice at E16.5 (Ect2F/wt $\mathrm{n}=3$

hearts, Ect2F/F n $=3$ hearts). (B) Genotypes and corresponding condition and number of pups recovered are listed. P-values were calculated using Fisher's exact test. Abbreviations used: F/F, flox/flox; F/Wt, flox/+. 


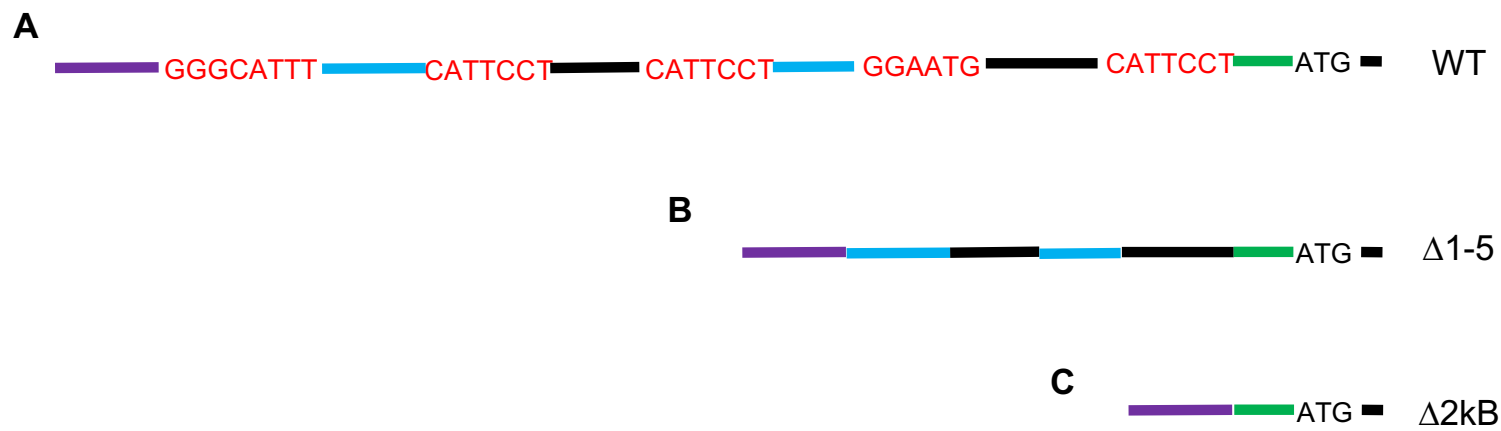

Figure S7. The wild type Ect2 promoter was modified to test the effect of the putative TEAD1/2-binding sites on the Ect2 promoter activity. (A) Five putative TEAD1/2-binding sites (red) were detected in the Ect2 promoter region through genome browser. (B) All five putative TEAD-binding sites were removed from the Ect2 promoter. (C) The continuous $2 \mathrm{kB}$ DNA sequence containing all the five TEAD-binding sites was removed. 


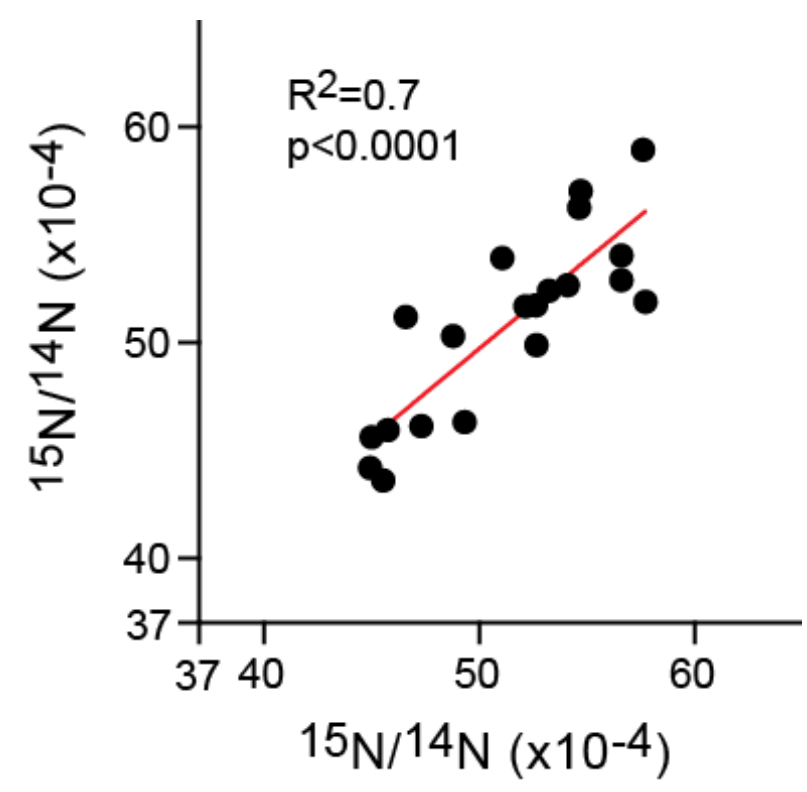

Figure S8. ${ }^{15} \mathrm{~N}$-thymidine labeling of binucleated cardiomyocytes. The degree of ${ }^{15} \mathrm{~N}$-thymidine labeling across all cardiomyocyte nuclei was variable, reflecting in part variable label exposure due to the kinetics of daily label administration. However, within individual nuclei of binucleated cardiomyocytes, the labeling was similar to that shown by the dot plot. Each dot represents a single binucleated cardiomyocyte, with the $\mathrm{X} / \mathrm{Y}$ coordinates representing the ${ }^{15} \mathrm{~N} /{ }^{14} \mathrm{~N}$ ratio for each member of the paired nuclei of the binucleated cardiomyocytes. The origin of the graph is at $37 \times 10^{-4}$, which is the natural background ratio of ${ }^{15} \mathrm{~N}$ relative to the more common stable isotopic variant, ${ }^{14} \mathrm{~N}$. 
A
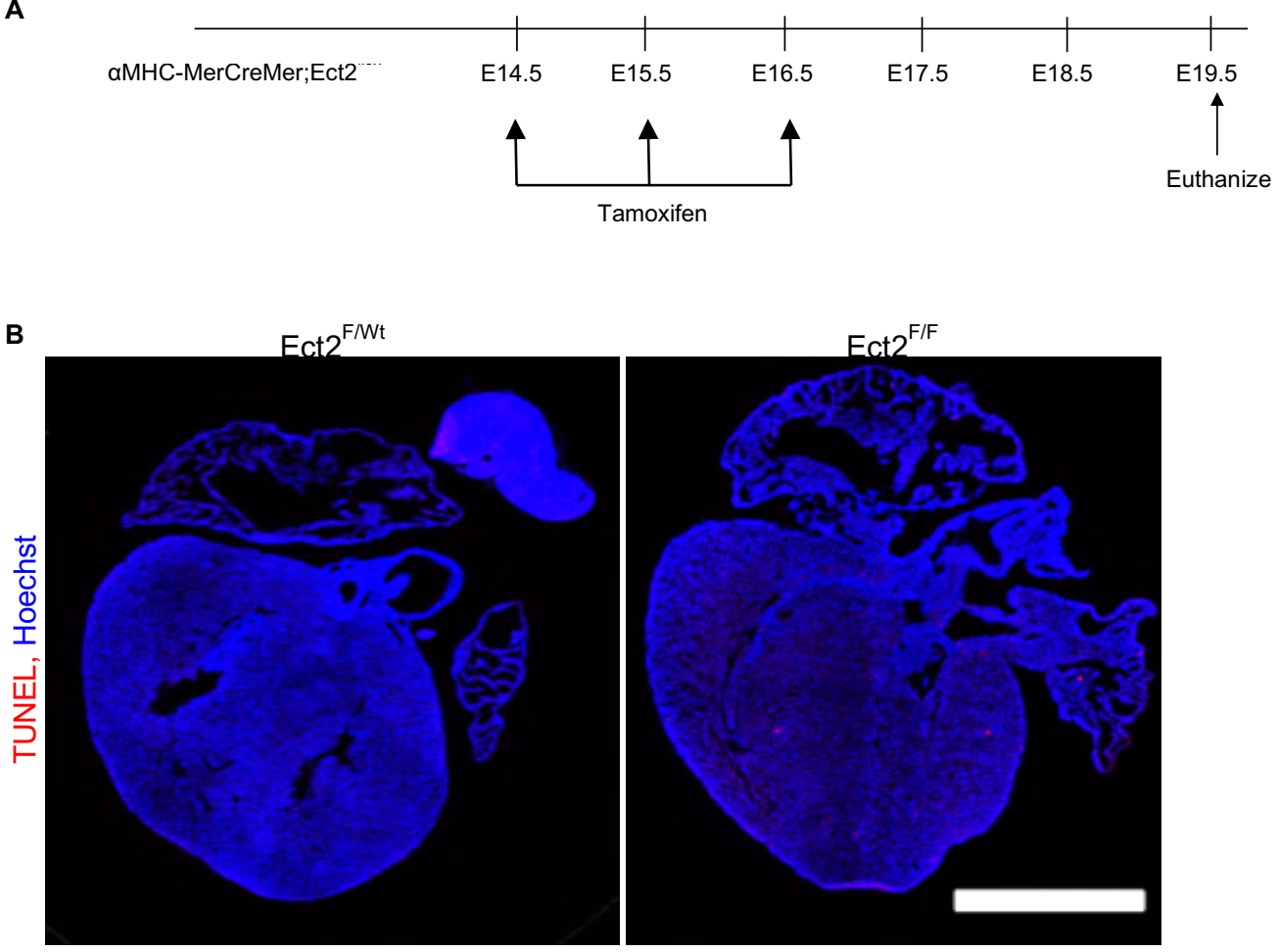

Figure S9. Inactivation of Ect2 gene in fetal cardiomyocytes does not induce apoptosis. (A) The Ect2flox gene in the mouse line $\alpha \mathrm{MHC}$-MerCreMer;Ect $2{ }^{\text {flox }}$ was inactivated through intraperitoneal (i.p.) injection of tamoxifen (30 $\mu \mathrm{g} / \mathrm{g}$ body weight) to pregnant dams on E14.5, 15.5, and 16.5. Pups were resected and analyzed at E19.5. (B) There is no evidence for cardiomyocyte apoptosis detected by TUNEL assay. Scale bar $1 \mathrm{~mm}$. 
Table S1. List of differentially expressed genes encoding 61 different Dbl-homology family Rho-GEF's between E14.5 and P5 cycling and non-cycling cardiomyocytes. Ect2 has a pvalue of $\leq 0.05$ and false discovery rate (FDR) of $\leq 10 \%$. This table was uploaded separately as an excel file. 
Table S2. Antibody manufacturers and dilutions

\begin{tabular}{llll}
\hline Antibody/dye & Manufacturer & Catalog number & $\begin{array}{l}\text { Dilution/ } \\
\text { concentration }\end{array}$ \\
\hline$\alpha$-actinin (sarcomeric) & Sigma & 7811 & $1: 500$ \\
\hline Cardiac Troponin I & Abcam & 56357 & $1: 200$ \\
\hline BrdU & Abcam & 6326 & $1: 400$ \\
\hline H3P, rabbit & Millipore & $06-570$ & $1: 200$ \\
\hline Hoechst & Invitrogen & H3570 & $1: 1,000$ \\
\hline Pan-Cadherin & Abcam & ab16505 & $1: 500$ \\
\hline Aurora B kinase & BD Transduction & 611083 & $1: 250$ \\
\hline Aurora B kinase & Laboratories & ab3609 & $1: 200$ \\
\hline Ect2 & Abcam & Sc-1005 & $1: 200$ \\
\hline RacGAP1 & Santa Cruz & PA5-22265 & $1: 200$ \\
\hline DAPI & Thermo Scientific & P36931 & $1: 1,000$ \\
\hline RhoA-GTP & Thermo Fisher & $1: 100$ \\
\hline
\end{tabular}




\section{Table S3. Image acquisition hardware and settings.}

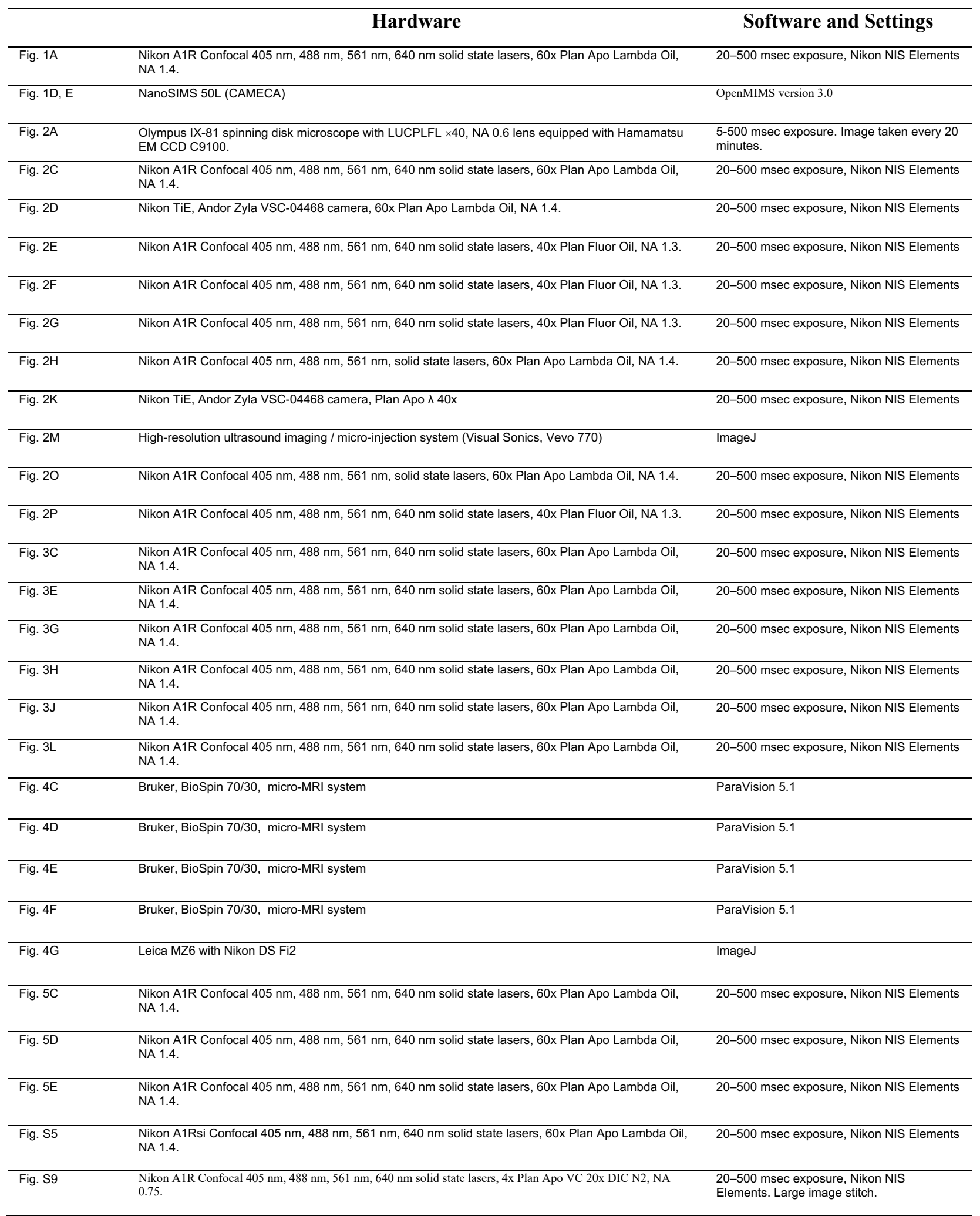


Table S4. Quantification of numeric data.

\begin{tabular}{|c|c|c|}
\hline Figure & Assay & Number of cardiomyocytes and/or hearts analyzed \\
\hline Fig. 1B-C & $\begin{array}{l}\text { Quantification of mono/bi/multi nucleated } \\
\text { cardiomyocytes in human subjects }\end{array}$ & $\begin{array}{l}\text { ToF/PS patient hearts, } n=12 \\
\text { No heart disease hearts, } n=5\end{array}$ \\
\hline Fig. 1F & $\begin{array}{l}{ }^{15} \mathrm{~N} \text {-thymidine }{ }^{+} \text {cardiomyocyte nucleation in ToF/PS } \\
\text { patients }\end{array}$ & $\begin{array}{l}\text { ToF/PS patients: } 1 \\
\text { Mononucleated cardiomyocytes analyzed: } 282 \\
\text { 15N+ mononucleated cardiomyocytes: } 25 \\
\text { Binucleated cardiomyocytes analyzed: } 104 \text { (208 total } \\
\text { nuclei) } \\
\text { 15N+ binucleated cardiomyocytes: } 20 \text { ( } 40 \text { total nuclei) }\end{array}$ \\
\hline Fig. 2A & Video microscopy & 52 cardiomyocytes \\
\hline Fig. 2C & $\begin{array}{l}\text { Cytokinesis assay: } \\
\text { AuroraB//RhoA-GTP colocalization }\end{array}$ & $\begin{array}{l}\text { E14.5: } 59 \text { Aurora B kinase positive midbodies } \\
\text { P2: } 56 \text { Aurora B kinase positive midbodies }\end{array}$ \\
\hline Fig. 2E & Binucleated BrdU+ cardiomyocytes & $\begin{array}{l}\text { GFP: } 407 \text { BrdU+ cardiomyocytes } \\
\text { GFP-Ect2: } 285 \text { BrdU+ cardiomyocytes }\end{array}$ \\
\hline Fig. 2F & BrdU+ cardiomyocytes & $\begin{array}{l}\text { GFP: } 432 \text { cardiomyocytes } \\
\text { GFP-Ect2: } 443 \text { cardiomyocytes }\end{array}$ \\
\hline Fig. 2G & $\mathrm{H} 3 \mathrm{P}+$ nuclei in cardiomyocytes & $\begin{array}{l}\text { GFP: } 54 \mathrm{H} 3 \mathrm{P}+\text { nuclei in } 2852 \text { cardiomyocyte nuclei } \\
\text { Ect2-GFP: } 59 \mathrm{H} 3 \mathrm{P}+\text { nuclei in } 3205 \text { cardiomyocyte nuclei }\end{array}$ \\
\hline Fig. $2 \mathrm{H}$ & Percentage of binucleated cardiomyocytes & $\begin{array}{l}\text { aMHC-Cre; Ect2 } 2^{\text {F/Nt }} \text { mice: } 6 \\
\text { aMHC-Cre; Ect2 } 2^{\text {F/F }} \text { mice: } 6\end{array}$ \\
\hline Fig. 2I & Percentage of cardiomyocyte nuclei & $\begin{array}{l}\text { aMHC-Cre; Ect2 } 2^{\mathrm{F} / \mathrm{Tt}} \text { mice: } 642 \text { cardiomyocytes } \\
\text { aMHC-Cre; Ect2 } 2^{\mathrm{F} / \mathrm{F}} \text { mice: } 647 \text { cardiomyocytes }\end{array}$ \\
\hline Fig. $2 \mathrm{~J}$ & Total number of the cardiomyocytes & $\begin{array}{l}\text { aMHC-Cre; Ect2 } 2^{F / t} \text { mice: } 12 \\
\text { aMHC-Cre; Ect2 }\end{array}$ \\
\hline Fig. $2 \mathrm{~K}$ & Cardiomyocyte size & $\begin{array}{l}\text { aMHC-Cre; Ect2 }{ }^{F / T t} \text { mice: } 1138 \text { cardiomyocytes } \\
\text { aMHC-Cre; Ect2 }\end{array}$ \\
\hline Fig. 2L & Heart-body weight ratio & $\begin{array}{l}\text { aMHC-Cre; Ect2 }{ }^{F / W t} \text { mice: } 14 \\
\text { aMHC-Cre; Ect2 }\end{array}$ \\
\hline Fig. 2M & Ejection fraction & $\begin{array}{l}\text { aMHC-Cre-; Ect2 }{ }^{\mathrm{WtWt}} \text { mice: } 4 \\
\text { aMHC-Cre+; Ect2 } 2^{\mathrm{F} / \mathrm{F}} \text { mice: } 3\end{array}$ \\
\hline Fig. $2 \mathrm{~N}$ & Pup survival & Fig. S6 \\
\hline Fig. 20 & $\mathrm{H} 3 \mathrm{P}+$ nuclei in cardiomyocytes & $\begin{array}{l}\text { aMHC-Cre; Ect2 }{ }^{\text {F/Wt }} \text { mice: } 6 \\
\text { aMHC-Cre; Ect2 }{ }^{\text {F/F }} \text { mice: } 6\end{array}$ \\
\hline Fig. 2P & BrdU+ cardiomyocytes & $\begin{array}{l}\text { Wild: } 2070 \text { BrdU- cells; } 84 \text { BrdU+ cells } \\
\text { Ect2KO: } 1522 \text { BrdU- cells; } 70 \text { BrdU+ cells }\end{array}$ \\
\hline Fig. 3A & Luciferase assay, Ect2 promoter activity & $\begin{array}{l}\text { WT: } 3 \text { cultures } \\
\Delta 1-5: 3 \text { cultures } \\
\Delta 2 \mathrm{kB}: 3 \text { cultures } \\
\text { Vector: } 3 \text { cultures }\end{array}$ \\
\hline Fig. 3B & qPCR Ect2 mRNA & $\begin{array}{l}\text { Scrambled siRNA: } 3 \text { cardiomyocyte isolations } \\
\text { TEAD1 siRNA: } 4 \text { cardiomyocyte isolations } \\
\text { TEAD2 siRNA: } 4 \text { cardiomyocyte isolations }\end{array}$ \\
\hline Fig. 3C & Percentage of binucleated cardiomyocytes & $\begin{array}{l}\text { Scrambled siRNA: } 3 \text { cardiomyocyte isolations } \\
\text { TEAD1 siRNA: } 4 \text { cardiomyocyte isolations } \\
\text { TEAD2 siRNA: } 4 \text { cardiomyocyte isolations }\end{array}$ \\
\hline Fig. 3D & qPCR Ect2 mRNA & $\begin{array}{l}\text { Adv-GFP: } 4 \text { cardiomyocyte isolations } \\
\text { Adv-YAP1-WT: } 4 \text { cardiomyocyte isolations } \\
\text { Adv-YAP1-S127A: } 4 \text { cardiomyocyte isolations }\end{array}$ \\
\hline Fig. 3E & Percentage of binucleated cardiomyocytes $\left(\mathrm{BrdU}^{+}\right)$ & $\begin{array}{l}\text { Adv-GFP: } 4 \text { cardiomyocyte isolations } \\
\text { Adv-YAP1-WT: } 4 \text { cardiomyocyte isolations } \\
\text { Adv-YAP1-S127A: } 4 \text { cardiomyocyte isolations }\end{array}$ \\
\hline Fig. 3F & qPCR Ect2 mRNA & $\begin{array}{l}\text { Control: } 5 \text { cardiomyocyte isolations } \\
\text { Forskolin: } 5 \text { cardiomyocyte isolations }\end{array}$ \\
\hline Fig. 3G & Percentage of multinucleated cardiomyocytes & $\begin{array}{l}\text { Control (P4 mice): } 6 \\
\text { Forskolin (P4 mice): } 6 \\
\text { Control (P8 mice): } 6 \\
\text { Forskolin (P8 mice): } 6\end{array}$ \\
\hline Fig. $3 \mathrm{H}$ & Percentage of multinucleated cardiomyocytes & $\begin{array}{l}\text { Wild: } 4 \text { hearts } \\
\text { DKO: } 4 \text { hearts }\end{array}$ \\
\hline Fig. 3I & Number of cardiomyocytes & $\begin{array}{l}\text { Wild: } 7 \text { hearts } \\
\text { DKO: } 5 \text { hearts }\end{array}$ \\
\hline Fig. 3J & Percentage of $\mathrm{H} 3 \mathrm{P}+$ cardiomyocytes & $\begin{array}{l}\text { Wild: } 4 \text { hearts } \\
\text { DKO: } 4 \text { hearts }\end{array}$ \\
\hline
\end{tabular}




\begin{tabular}{|c|c|c|}
\hline Fig. 3K & Taqman assay & $\begin{array}{l}\text { Wild: } 3 \text { hearts } \\
\text { DKO: } 3 \text { hearts }\end{array}$ \\
\hline Fig. 3L & Percentage of multinucleated cardiomyocytes & $\begin{array}{l}\text { Control (P4 mice): } 6 \\
\text { Propranolol (P4 mice): } 6 \\
\text { Control (P8 mice): } 6 \\
\text { Propranolol (P8 mice): } 6\end{array}$ \\
\hline Fig. 3M & Total number of the cardiomyocytes & $\begin{array}{l}\text { Control (P4 mice): } 7 \\
\text { Propranolol (P4 mice): } 6 \\
\text { Control (P8 mice): } 4 \\
\text { Propranolol (P8 mice): } 4\end{array}$ \\
\hline Fig. 3N & $\mathrm{H} 3 \mathrm{P}+$ nuclei in cardiomyocytes & $\begin{array}{l}\text { Control (P4 mice): } 6 \\
\text { Propranolol (P4 mice): } 6\end{array}$ \\
\hline Fig. 30 & Heart-body weight ratio & $\begin{array}{l}\text { Control (P4 mice): } 7 \\
\text { Propranolol (P4 mice): } 6 \\
\text { Control (P8 mice): } 4 \\
\text { Propranolol (P8 mice): } 4\end{array}$ \\
\hline Fig. 4A & Percentage of Ejection Fraction & $\begin{array}{l}\text { Control (PBS): } 11 \\
\text { Propranolol: } 6\end{array}$ \\
\hline Fig. 4C & Percentage of Ejection Fraction & $\begin{array}{l}\text { Control (PBS): } 5 \\
\text { Propranolol: } 4\end{array}$ \\
\hline Fig. 4D & $\begin{array}{l}\text { Percentage of LV wall thinning caused by adverse } \\
\text { remodelling }\end{array}$ & $\begin{array}{l}\text { Control (PBS): } 5 \\
\text { Propranolol: } 4\end{array}$ \\
\hline Fig. 4E & Percentage of LV wall thickening & $\begin{array}{l}\text { Control (PBS): } 5 \\
\text { Propranolol: } 4\end{array}$ \\
\hline Fig. 4F & Percentage of Myocardial infarction & $\begin{array}{l}\text { Control (PBS): } 5 \\
\text { Propranolol: } 4\end{array}$ \\
\hline Fig. 4G & Scar size & $\begin{array}{l}\text { Control (PBS): } 5 \\
\text { Propranolol: } 4\end{array}$ \\
\hline Fig. $4 \mathrm{H}$ & Total number of cardiomyocytes & $\begin{array}{l}\text { Control (PBS): } 5 \\
\text { Propranolol: } 5\end{array}$ \\
\hline Fig. 4I & Heart-body weight ratio & $\begin{array}{l}\text { Control (PBS): } 5 \\
\text { Propranolol: } 6\end{array}$ \\
\hline Fig. $5 \mathrm{~A}$ & Expression of Ect2 mRNA & $\begin{array}{l}\text { ToF/PS: } 13 \text { cardiomyocytes } \\
\text { Fetal: } 71 \text { cardiomyocytes }\end{array}$ \\
\hline Fig. 5B & Percentage of Ect2 positive cells & $\begin{array}{l}\text { ToF/PS: } 4 \text { heart samples } \\
\text { Fetal: } 3 \text { heart samples }\end{array}$ \\
\hline Fig. 5C & $\begin{array}{l}\text { Cardiomyocyte binucleation }\left(\mathrm{BrdU}^{+}\right) \text {of cultured } \\
\text { human fetal hearts }\end{array}$ & $\begin{array}{l}\text { Control: } 4 \text { hearts } \\
\text { Forskolin: } 4 \text { hearts } \\
\text { Dobutamine: } 4 \text { hearts } \\
\text { Dobutamine+Propranolol: } 4 \text { hearts } \\
\text { Propranolol: } 4 \text { hearts }\end{array}$ \\
\hline Fig. 5D & Percentage of Ect2+ midbodies & $\begin{array}{l}\text { Forskolin: } 27 \text { midbodies } \\
\text { Dobutamine: } 55 \text { midbodies } \\
\text { Dobutamine: } 26 \text { midbodies }\end{array}$ \\
\hline Fig. 5E & $\begin{array}{l}\text { Cardiomyocyte binucleation }\left(\mathrm{BrdU}^{+}\right) \text {of cultured } \\
\text { myocardium from ToF/PS patients }\end{array}$ & $\begin{array}{l}\text { Forskolin: } 3 \text { hearts } \\
\text { Dobutamine: } 3 \text { hearts } \\
\text { Dobutamine+Propranolol: } 3 \text { hearts } \\
\text { Propranolol: } 3 \text { hearts }\end{array}$ \\
\hline
\end{tabular}


Table S5. PCR primers and 5'-3' oligonucleotides

\begin{tabular}{l|l|l}
\hline Gene & Forward & Reverse \\
\hline Mouse Ect2 & \multicolumn{2}{|c}{ mRNA } \\
\hline Mouse $\beta$-actin & 5'-CATTGCTGACAGGATGCAGAAGG-3' & 5'-CCTTTGGAAGCTCCTCTGACGT-3' \\
\hline Mouse GAPDH & 5'-CATCACTGCCACCCAGAAGACTG-3' & 5'-ATGCCAGTGAGCTTCCCGTTCAG-3' \\
\hline Rat Ect2 & 5'- CGCAAGGAGAAAAGTTTAGGG-3' & 5'- CATCCTGGCCTCATAATTGG-3' \\
\hline Rat Racgap1 & 5'-TTCAAAATGAAGAAACGAGAAAAG-3' & 5'- AGGGCCATCGATGAACTGT-3' \\
\hline Rat MKLP1 & 5'- TGGACCGATGTAGAAACAAGG-3' & 5'- GTTGTGCGTGGTGCTGAT-3' \\
\hline Rat GEF-H1 & 5'-CGGATCGAATCCCTCACTC-3' & 5'- TCTCCTTTTCCCGGGTCTT-3' \\
\hline Rat $\beta$-actin & 5'-CCCGCGAGTACAACCTTCT-3' & 5'- CGTCATCCATGGCGAACT-3' \\
\hline Rat GAPDH & 5'-GGCAAGTTCAACGGCACAGT-3' & 5'- TGGTGAAGACGCCAGTAGACTC-3' \\
\hline Mouse Rosa26 & 5'-CGTTTCCGACTTGAGTTGCC-3' & 5'-ACTCGGGTGAGCATGTCTTT-3' \\
\hline Mouse Ect2' ${ }^{\text {flox }}$ & 5'-TCCTCCGGGTG GACCAGAG-3' & 5'-CTGGCTTCATAATTGGAG TGC-3' \\
\hline
\end{tabular}


Table S6. Animal strains used in this study

\begin{tabular}{|c|c|c|}
\hline Gene & Species & Source \\
\hline FUCCl-red(mKO2-cdt1) & Mouse, C57BL/6 & Miyawaki Lab, RIKEN Institute, Japan \\
\hline FUCCl-green(mAG-Geminin) & Mouse, C57BL/6 & Miyawaki Lab, RIKEN Institute, Japan \\
\hline Ect2 ${ }^{\mathrm{F} / \mathrm{F}}$ & Mouse, C57BL/6 & $\begin{array}{l}\text { Provided by Dr. Channing Der (University of } \\
\text { North Carolina Chapel Hill) }\end{array}$ \\
\hline aMHC-Cre & Mouse, C57BL/6 & The Jackson Laboratory \\
\hline aMHC-MerCreMer & Mouse, C57BL/6 & The Jackson Laboratory \\
\hline$\beta M H C-Y F P($ Knock-in) & Mouse, C57BL/6 & $\begin{array}{l}\text { Oliver Smithies University of North Carolina } \\
\text { Chapel Hill (PNAS) }\end{array}$ \\
\hline $\begin{array}{l}\text { FUCCI-green(mAG-Geminin); } \\
\text { ßMHC-YFP }\end{array}$ & Mouse, C57BL/6 & $\begin{array}{l}\text { Crossbreeding FUCCl-green(mAG-Geminin) } \\
\text { mice with } \beta M H C-Y F P \text { mice }\end{array}$ \\
\hline aMHC-Cre; Ect2 ${ }^{\text {Flox }}$ & Mouse, C57BL/6 & $\begin{array}{l}\text { Crossbreeding aMHC-Cre mice with Ect2 }{ }^{\text {Flox }} \\
\text { mice }\end{array}$ \\
\hline aMHC-MerCreMer; Ect2Flox & Mouse, C57BL/6 & $\begin{array}{l}\text { Crossbreeding aMHC-MerCreMer mice with } \\
\text { Ect2 } 2^{\text {Flox mice }}\end{array}$ \\
\hline $\begin{array}{l}\text { FUCCI-red (mKO2-cdt1; } \\
\text { FUCCl-green(mAG-Geminin) }\end{array}$ & Mouse, C57BL/6 & $\begin{array}{l}\text { Crossbreeding FUCCl-red(mKO2-cdt1) mice } \\
\text { with FUCCl-green(mAG-Geminin) mice }\end{array}$ \\
\hline$\beta 1-\mathrm{AR}^{-1-} ; \beta 2-\mathrm{AR}^{-1-}$ & $\begin{array}{l}\text { Mouse, C57BL/6 and } \\
\text { (129X1/SvJ x } \\
\text { 129S1/Sv)F1-Kitl }\end{array}$ & The Jackson Laboratory \\
\hline Wild type & Mouse, ICR (CD-1) & Charles River \\
\hline Wild type & Rat, Sprague Dawley & Charles River \\
\hline
\end{tabular}


Table S7. Clinical information corresponding to human samples*

\begin{tabular}{|c|c|c|c|c|c|}
\hline $\begin{array}{l}\text { Subject } \\
\text { number }\end{array}$ & Age & Gender & Cardiac Diagnosis & Site & \\
\hline 1 & 14 days & $\mathrm{F}$ & ToF/PS & $\mathrm{RV}$ & \multirow{12}{*}{ Figure $1 \mathrm{~B}, 1 \mathrm{C}$} \\
\hline 2 & 4 weeks & NA & ToF/PS & $\mathrm{RV}$ & \\
\hline 3 & 1.25 months & M & ToF/PS & RV & \\
\hline 4 & 1.25 months & NA & ToF/PS & $\mathrm{RV}$ & \\
\hline 5 & 1.5 months & NA & ToF/PS & RV & \\
\hline 6 & 2 months & $\mathrm{F}$ & ToF/PS & RV & \\
\hline 7 & 2 months & $\mathrm{M}$ & ToF/PS & RV & \\
\hline 8 & 4 months & $M$ & ToF/PS & $\mathrm{RV}$ & \\
\hline 9 & 5 months & M & ToF/PS & RV & \\
\hline 10 & 6 months & M & ToF/PS & $\mathrm{RV}$ & \\
\hline 11 & $6 y e a r s$ & M & ToF/PS & $\mathrm{RV}$ & \\
\hline 12 & 13 years & $\mathrm{F}$ & ToF/PS & $\mathrm{RV}$ & \\
\hline 13 & 7 months & M & ToF/PS & $\mathrm{RV}$ & Figure 1D \\
\hline $\begin{array}{l}\text { Subject } \\
\text { number }\end{array}$ & $\begin{array}{c}\text { Fetal } \\
\text { gestational } \\
\text { age }\end{array}$ & Gender & Cardiac Diagnosis & Site & \\
\hline 14 & 22 week & Not available & None & Ventricular region & \multirow{4}{*}{ Figure 5C } \\
\hline 15 & 18 week & Not available & None & Ventricular region & \\
\hline 16 & 20 week & Not available & None & Ventricular region & \\
\hline 17 & 21 week & Not available & None & Ventricular region & \\
\hline 18 & 23 week & Not available & None & Ventricular region & Figure 5D \\
\hline $\begin{array}{l}\text { Subject } \\
\text { number }\end{array}$ & Age & Gender & Cardiac Diagnosis & Site & \multirow{4}{*}{ Figure 5E } \\
\hline 19 & 5 months & M & ToF/PS & $\mathrm{RV}$ & \\
\hline 20 & 4.5 months & M & ToF/PS & RV & \\
\hline 21 & 3 weeks & $\mathrm{F}$ & ToF/PS & RV & \\
\hline
\end{tabular}

*Age, gender, cardiac diagnosis and site of myocardium resection are provided. Abbreviations used: ToF/PS, Tetralogy of Fallot with pulmonary stenosis; RV, right ventricle; NA, not available. 
Table S8. Ejection fraction of newborn (P0) mice $\alpha \mathrm{MHC}-\mathrm{Cre}$; ect $^{\text {flox }}$ pups.

Echocardiography was performed with a Visual Sonics 770. Statistical significance was tested with t test.

\begin{tabular}{|c|c|c|c|c|c|}
\hline Method & Litter\# & Mouse\# & Genotype & $\begin{array}{c}\text { Ejection } \\
\text { fraction (\%) }\end{array}$ & $P$-value \\
\hline \multirow{7}{*}{ Echocardiography } & \multirow{6}{*}{1} & 1 & \multirow{4}{*}{$\begin{array}{l}\text { aMHC-Cre-; Ect2 } \text { flox }^{\text {(Wild) }}\end{array}$} & 90.03 & \multirow{7}{*}{0.0068} \\
\hline & & 2 & & 85.41 & \\
\hline & & 3 & & 85.70 & \\
\hline & & 4 & & 82.42 & \\
\hline & & 5 & \multirow{3}{*}{ 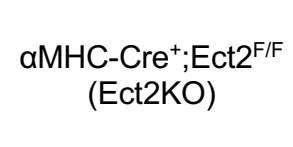 } & 66.72 & \\
\hline & & 6 & & 32.39 & \\
\hline & 2 & 7 & & 42.43 & \\
\hline
\end{tabular}


Video S1. Live cell imaging in NRVM shows that cleavage furrow regression precedes formation of binucleation. Neonatal rat ventricular cardiomyocytes (NRVM) were imaged by live cell microscopy. Midbody formation is evident between 300-335 minutes, cleavage furrow regression at 355 minutes, and formation of a binucleated cardiomyocyte at 510 minutes.

Video S2. Live cell imaging of a neonatal cardiomyocyte undergoing division. Neonatal cardiomyocytes were isolated from mice expressing both elements of the FUCCI reporter in which Cdt1 fused to Orange Fluorescent Protein (Cdt1-mKO2) indicates G1 phase in red, and Geminin fused to Green Fluorescent Protein (mAG-hGem) indicates S-, G2-, and M-phase in green. The video starts with a single cardiomyocyte nucleus in green, indicating that it is in S-, G2-, or M-phase. After division, the cardiomyocyte nucleus turns to red, indicating that it has exited the cell cycle. The last frame is the result of immunofluorescence staining showing BrdUuptake (blue) and sarcomers stained with $\alpha$-actinin (red).

Video S3. Live cell imaging of a neonatal cardiomyocyte undergoing cytokinesis failure. Neonatal cardiomyocytes were isolated from mice expressing both elements of the FUCCI reporter in which Cdt1 fused to Orange Fluorescent Protein $(\mathrm{Cdt} 1-\mathrm{mKO} 2)$ indicates G1 phase in red, and Geminin fused to Green Fluorescent Protein (mAG-hGem) indicates S-, G2-, and Mphase in green. The video starts with a single cardiomyocyte nucleus in green, indicating that it is in S-, G2-, or M-phase. The cell does not divide, both daughter nuclei move together and reaccumulate Cdt1-mKO2, indicating that it has exited the cell cycle. The cells were cultured in the presence of BrdU, whose uptake shows that this cardiomyocyte was in S-phase at the beginning of the video.

Video S4. Live cell imaging shows appropriate and dynamic localization of GFP-Ect2 
during the cell cycle. NRVM were transduced with adenovirus leading to expression of Ect2GFP AdV and imaged every 10 minutes. The video shows that GFP-Ect2 is located in the nucleus in interphase ( 0 minutes), in the cleavage furrow during cytokinesis (60 minutes), in the midbody during abscission (90 minutes), and is associated with completion of cytokinesis (140 minutes).

Video S5. Ect2 inactivation induces heart failure and death of newborn mice. Newborn $\alpha \mathrm{MHC}-\mathrm{Cre}^{+} ;$Ect $^{\text {flox } / \text { flox }}$ mice $(\mathrm{P} 0)$ were pale and cool, compared with $\alpha \mathrm{MHC}-\mathrm{Cre}^{+} ; \mathrm{Ect} 2^{\text {flox } /+}$ littermates. This mouse (red arrow) died within 48 hours after birth as a result of heart failure.

Video S6. Heart function of the newborn (P0) wild type mouse pup. Two-dimensional (2D) B-mode echocardiography recordings covering both ventricles of a newborn (P0) wild type mice shows an ejection fraction of $85.9 \%$.

Video S7. Heart function of the newborn (P0) mouse pup with Ect2 knockout. Twodimensional (2D) B-mode echocardiography recordings covering both ventricles of a newborn (P0) mice with Ect2 knockout shows an ejection fraction of $49.6 \%$. 


\section{References for Supplemental Material}

1. Mollova M, Bersell K, Walsh S, et al. Cardiomyocyte proliferation contributes to heart growth in young humans. Proceedings of the National Academy of Sciences of the United States of America 2013;110:1446-51.

2. Sakaue-Sawano A, Kurokawa H, Morimura T, et al. Visualizing spatiotemporal dynamics of multicellular cell-cycle progression. Cell 2008;132:487-98.

3. Pandya K, Kim HS, Smithies O. Fibrosis, not cell size, delineates beta-myosin heavy chain reexpression during cardiac hypertrophy and normal aging in vivo. Proc Natl Acad Sci U S A 2006;103:16864-9.

4. Agah R, Frenkel PA, French BA, Michael LH, Overbeek PA, Schneider MD. Gene recombination in postmitotic cells. Targeted expression of Cre recombinase provokes cardiacrestricted, site-specific rearrangement in adult ventricular muscle in vivo. J Clin Invest 1997;100:169-79.

5. Cook DR, Solski PA, Bultman SJ, et al. The ect2 rho Guanine nucleotide exchange factor is essential for early mouse development and normal cell cytokinesis and migration. Genes Cancer 2011;2:932-42.

6. Bolger AM, Lohse M, Usadel B. Trimmomatic: a flexible trimmer for Illumina sequence data. Bioinformatics 2014;30:2114-20.

7. Kim D, Langmead B, Salzberg SL. HISAT: a fast spliced aligner with low memory requirements. Nat Methods 2015;12:357-60.

8. Anders S, Pyl PT, Huber W. HTSeq--a Python framework to work with high-throughput sequencing data. Bioinformatics 2015;31:166-9.

9. Li M, Rao M, Chen K, Zhou J, Song J. Selection of reference genes for gene expression studies in heart failure for left and right ventricles. Gene 2017;620:30-5.

10. Su KC, Takaki T, Petronczki M. Targeting of the RhoGEF Ect 2 to the equatorial membrane controls cleavage furrow formation during cytokinesis. Dev Cell 2011;21:1104-15. 11. Hayashi K, Yonemura S, Matsui T, Tsukita S. Immunofluorescence detection of ezrin/radixin/moesin (ERM) proteins with their carboxyl-terminal threonine phosphorylated in cultured cells and tissues. J Cell Sci 1999;112 ( Pt 8):1149-58.

12. Nishimura Y, Yonemura S. Centralspindlin regulates ECT2 and RhoA accumulation at the equatorial cortex during cytokinesis. Journal of cell science 2006;119:104-14.

13. Steinhauser ML, Bailey AP, Senyo SE, et al. Multi-isotope imaging mass spectrometry quantifies stem cell division and metabolism. Nature 2012;481:516-9.

14. Guillermier C, Fazeli PK, Kim S, et al. Imaging mass spectrometry demonstrates agerelated decline in human adipose plasticity. JCI Insight 2017;2:e90349.

15. Senyo SE, Steinhauser ML, Pizzimenti CL, et al. Mammalian heart renewal by preexisting cardiomyocytes. Nature 2013;493:433-6.

16. Guillermier C, Poczatek JC, Taylor WR, Steinhauser ML. Quantitative imaging of deuterated metabolic tracers in biological tissues with nanoscale secondary ion mass spectrometry. International Journal of Mass Spectrometry 2017;422:9. 